\title{
The Pragmatic Role of Iconic Buildings in Promoting Social Engagement: A Case Study of Sage Gateshead Music Centre, Newcastle upon Tyne, UK
}

\author{
By Xi Ye*
}

Creating cultural-led iconic buildings has become a model that political and economic institutions seek to present a cultural narration of a transformation of local economics associated with urban regenerations. Symbolic appearance has been laid much emphasis on iconic buildings, as it tends to attract visual consumers rather than actual users. However, the question is after iconic buildings have attracted people, what they can do next to function well. Thus, to a cultural-led iconic building, there should be a pragmatic role in developing social life other than a symbolic role only. This article intends to explore the pragmatic role of cultural-led iconic buildings in promoting social engagement - first, how the idea of social engagement takes part in the way of searching for the design concept, and second, how the building actually functions to improve social engagement in everyday life. Sage Gateshead music centre is a key project in the regeneration of Newcastle-Gateshead quayside in the Northeast England. The symbolic form of the building is not the only issue that the architect took into account; the idea of social engagement was also taken into the consideration of finding the design concept, as it is conceptually proposed to create an "Urban Living Room", and this concept was technically inscribed in spatial forms. The actual experience in the building is in some way echoing the design concept. The building performs exactly as an "Urban Living Room" where diverse events happen and different social groups encounter. Therefore, Sage Gateshead Music Centre acts as a positive example that interprets the pragmatic role of iconic buildings in promoting social engagement.

\section{The Two Roles of Iconic Buildings}

There are usually two dimensions to iconic buildings - symbolic and functional. In urban iconic buildings the symbolic image has been seen to be more important, because they have such a prominent presence in the urban landscape. Appearance is a determining factor in how the public to respond to their surroundings. Thus, architects sometimes focus more on how buildings look than on how they are actually used. These iconic buildings are positioned in relation to visual consumers instead of actual users. ${ }^{1}$ Surface appearance and visual effects are more important in this case, so that buildings are designed from the outside in, from the vantage point of the external gaze. It is not only architects who are striving to search for symbolic meanings and translate these

\footnotetext{
*Lecturer, Macau University of Science and Technology, Macau.

1. Paul Jones, The Sociology of Architecture (Liverpool: Liverpool University Press, 2011), 120.
} 
meanings into the symbolic forms of the building; city managers also have to decide what kinds of meaning could be linked to the city as a brand in the form of iconic buildings. ${ }^{2}$

There is a tendency for urban regeneration projects to have iconic buildings with socially or culturally meaningful components as their central focus, because to promote a city as a cultural hub seems to be an effective way of promoting economic growth, and, where the iconic image tends to dominate, cultural consumption usually plays a particular role as the most visible aspect of a symbolic economy. ${ }^{3}$ Therefore, producing iconic buildings for urban regeneration projects becomes a model in re-imaging cities and in creating new tourist destinations. The opening of the Guggenheim Museum in Bilbao marked a flagship of re-imaging the city with a focusing on an iconic building for economic and cultural purposes and achieved remarkable success, since named the "Bilbao effect." After that, numerous iconic buildings mushroomed all over the world. In the UK, Imperial War Museum North in Manchester designed by Daniel Libeskind (Figure 1), Sage Gateshead music centre in Newcastle designed by Norman Forster and Wales Millennium Centre in Cardiff designed by Jonathan Adams are typical examples. All of these projects were accomplished at the beginning of the $21^{\text {st }}$ century; each associated with larger-scale regeneration plans for declining industrial sites. The symbolic features of these buildings bring visual distinctiveness to the declining sites, and their cultural features accessible to the public generate new events and social life that enable obsolete sites to be revived. The involvement of iconic buildings in urban regeneration projects reflects the fact that political and economic institutions are seeking to present a culturally and socially meaningful narrative of the transformation of local economics, and the increasing production of iconic buildings which are expected to be visibly dominant implies a transnational approach that contributes to city images through their visual effect. ${ }^{5}$

2. María A. Sainz, “(Re)Building an Image for a City: Is A Landmark Enough? Bilbao and the Guggenheim Museum 10 Years Together," Journal of Applied Social Psychology 42, no. 1 (2012): 115.

3. Steven Miles and Malcolm Miles, Consuming Cities (New York: Palgrave Macmillan, 2004), 45 .

4. Jones, The Sociology of Architecture, 2011, 116-17.

5. Ibid, 118. 


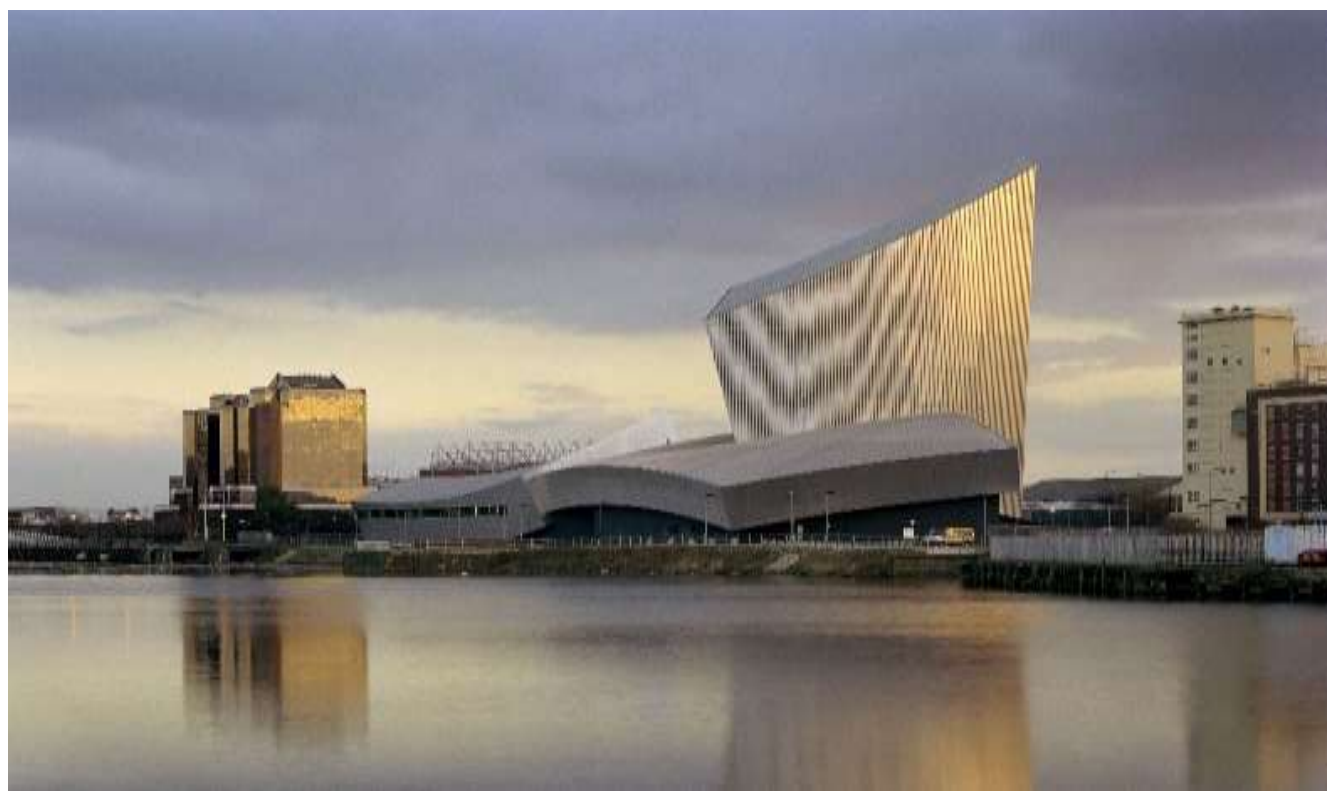

Figure 1. Imperial War Museum North

Source: http://libeskind.com/work/imperial-war-museum-north/.

As cultural institutions are signs of urban affluence. So cultural facilities, such as museums, art galleries or concert halls, can promote the iconic status of a place in a conceptual way, as the cultural capital which was planted into a building is helpful to the building's reputation and thus the building will become a "mental icon" in people's minds instead of a visual icon. This is why culture-led iconic buildings are the main components in regeneration projects. For some buildings, such as Sage Gateshead and Centre Pompidou, both the symbolic image of the building and its cultural reputation are public attractions. There are buildings, such as Tate Modern and British Museum, that have a symbolic role without their building's appearance being crucial to it (Figures 2 and 3). They act more as "mental icons", since their visual appearance is second to their cultural reputation.

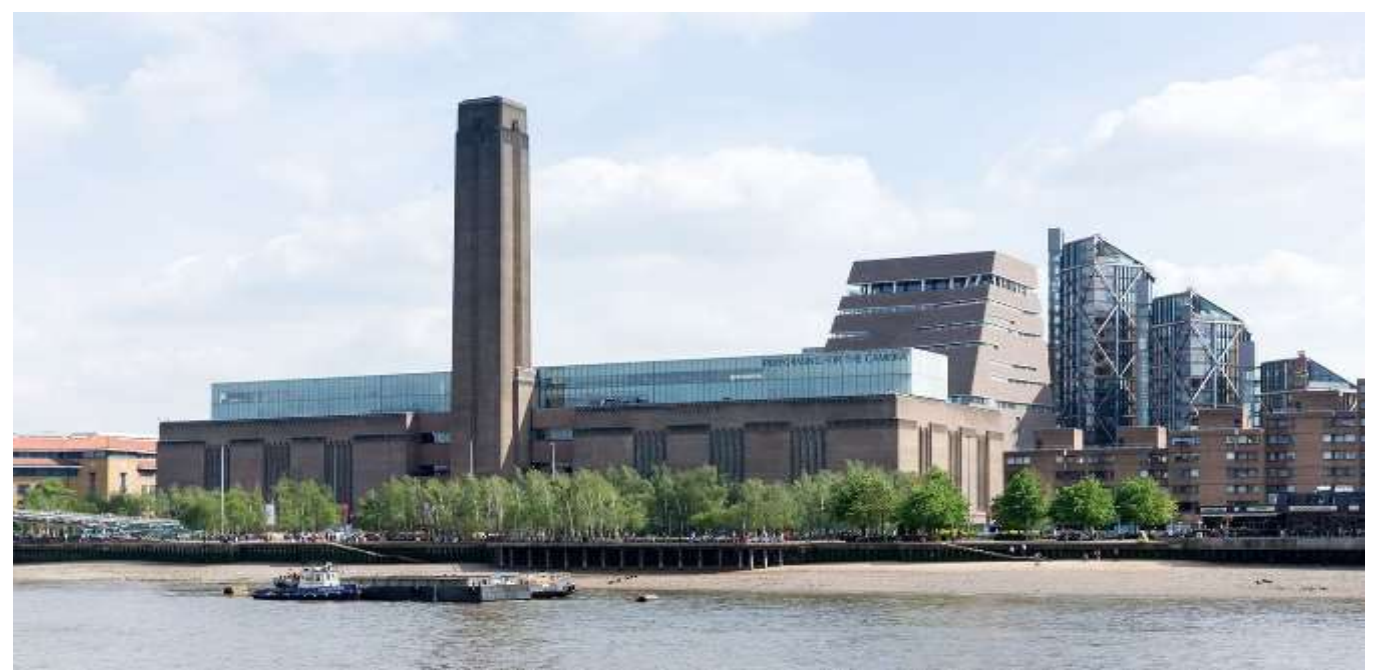

Figure 2. Tate Modern

Source: https://bit.ly/2qrKPkE. 


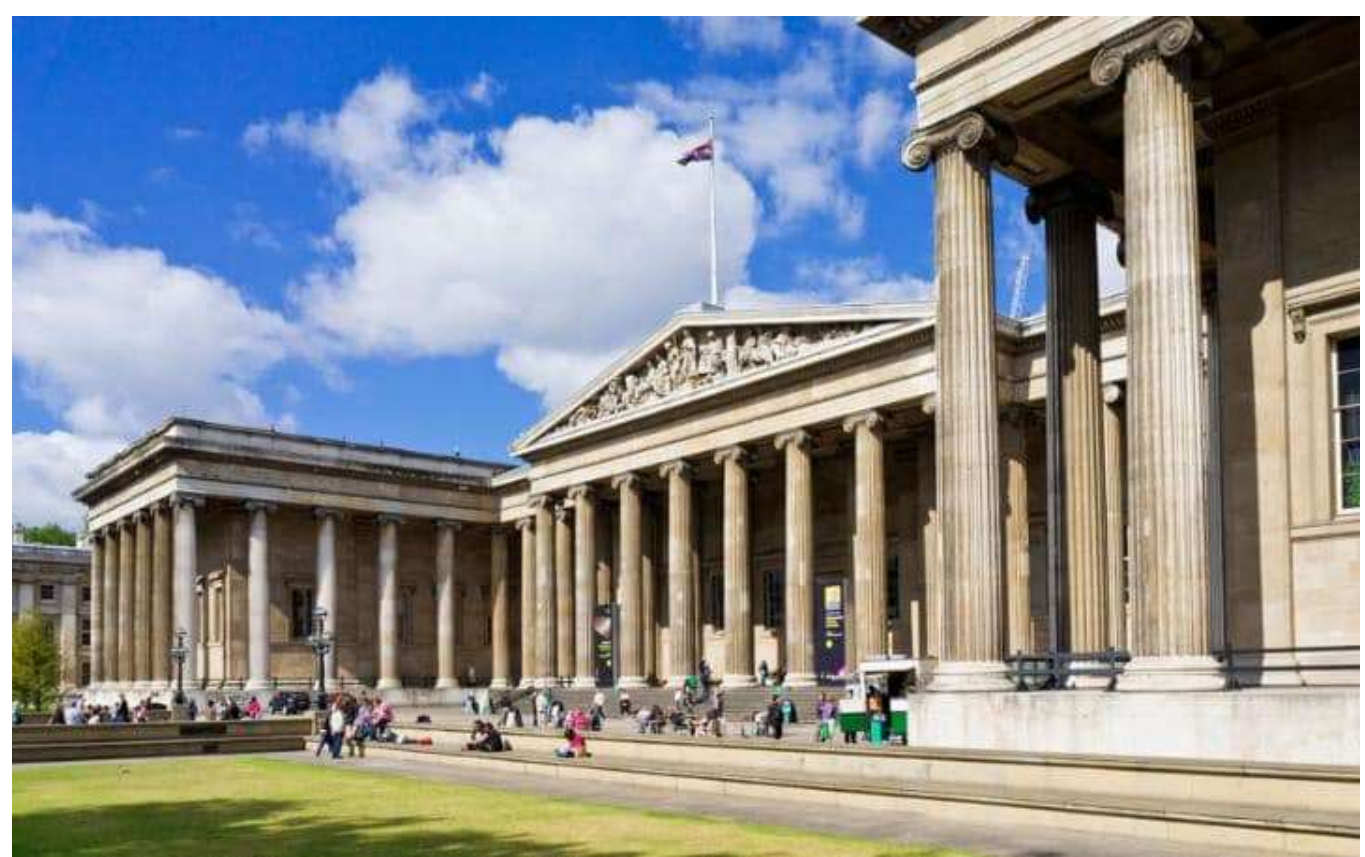

Figure 3. British Museum

Source: https://bit.ly/1LLasGG.

Iconic buildings seem to be responsible for representing a city's image and bringing development opportunities through their symbolic purposes rather than through functional purposes. However, these two dimensions of symbolism and functionalism are not contradictory. The symbolic image of the building signifies its cultural status in the city, which brings the building a reputation and benefits the city's fortunes. In the meantime, an eye-catching symbolic form can attract public attention, thus bringing more public life to a place and generating a more vibrant and friendly urban atmosphere. If the interior space of the building is organised well, it will become an attractive place for social contact, as can outdoor spaces; hence, both the interior of an iconic building and its surroundings can play an important role in improving public life. In this sense, the form of iconic buildings also has the capacity to activate urban public life, and thus it performs a pragmatic role. People might be attracted by the symbolic appearance of the building at first, but the building is then able to demonstrate a pragmatic end. Therefore, when architects are developing their design concepts, they can (and should) take actual use into consideration rather than being concerned with symbolic appearance only. Their concepts could be created from the intention to contribute to social inclusion, community life, public communication and the like.

According to Richard Sennett, cities have for centuries provided places where human beings could focus their social aspirations, experience the interplay of interests and test the possibilities of human life. ${ }^{6}$ However, they are not serving that function now. Due to the impacts of secularisation and industrial capitalism, people have slowly destroyed the "public realm". The public realm becomes more intense and less sociable. For Sennett, a city is a place where strangers meet. It

6. Richard Sennett, The Fall of Public Man (London: Penguin, 2003), xvi-xxi. 
should be "the forum in which it becomes meaningful to join with other persons without the compulsion to know them as persons". Since the rise of secularisation, the loss of the belief in gods, and the cult of personality, social change has resulted in the loss of the public realm. However, Sennett believes it can be reinstated once more, but only if "public man" can somehow be resurrected. A well-designed spatial setting might in some way resurrect "public man", as spatial settings can induce social contact between people. Spatial settings have catalytic effects on social contact, not just targeted at one or the same activity, but allowing everyone to behave in accordance with their own intentions and movements and so be given opportunities to seek out their own spaces in relation to others there. It is social contact that turns collective spaces into social spaces. What needs to be found are spatial forms that are well organised so that they offer greater opportunities and causes for social contact.

Urban public realms can be found wherever we live, work and interact, serving as the main social contact generator. What we call public life is enacted not only in open-air urban space, but also in publicly used buildings. ${ }^{7}$ So, as well as streets and squares, there are theatres, museums, stadiums and stations that are used by large numbers of people. Usually culture-led iconic buildings are functioning as galleries, museums or music centres, which are good communal places for public gathering and encounter. These culture-led iconic buildings can offer great chances of social encounter for strangers who see, are seen and share the same activities. Those buildings which have iconic roles have greater potential to attract the public visually. But, after the buildings have attracted people, what they should do next to function well, thus generating and reinforcing a better social life, is a more essential matter. Although visual forms play an important role in making a city's identity, functional terms should always be the essence of architecture since whether or not a public space is used well is related much more to the quality of the space.

This paper studies Sage Gateshead music centre, an iconic building located in Newcastle upon Tyne UK, designed by Norman Foster and partners, as a positive case interpreting the pragmatic role of iconic buildings in promoting social life. The architect chose certain social values according to relevant contexts and transplant them into design concepts, through which buildings become socially meaningful - the concept of making an "Urban Living Room" in Sage Gateshead comes from the social expectation of regenerating Gateshead quayside to be a public and vibrant place. Architects then technically design physical spaces based on those concepts. Architects seeking to embody social values in building forms, especially the interventions of high-profile architects in public debates in the most noticeable form of iconic buildings, is a key way in which particular buildings are endowed with social meanings. ${ }^{8}$ Sage Gateshead music centre, which is attractive for its noticeable form and the high-profile designer, convey a strong social meaning of publicness and inclusiveness through the design of large public accessible spaces and various social engagement programmes. Thus, when people

7. Herman Hertzberger, Space and the Architect: Lessons in Architecture 2 (Rotterdam: 010 Publishers, 2000), 134.

8. Jones, The Sociology of Architecture, 2011, 30. 
encounter these buildings and take part in programmes, they may realise the meaning that the buildings are attempting to express.

\section{"Urban Living Room": The Pragmatic Role of Sage Gateshead}

Sage Gateshead music centre is located on Gateshead quayside by the River Tyne on what had once been a flourishing industrial site. The building plays a key role in the regeneration of Newcastle Gateshead quaysides by offering an iconic appearance and new cultural hub to the public. Before going into detail about its architecture, it is necessary to consider the regeneration context of the Newcastle Gateshead quaysides (Figure 4).

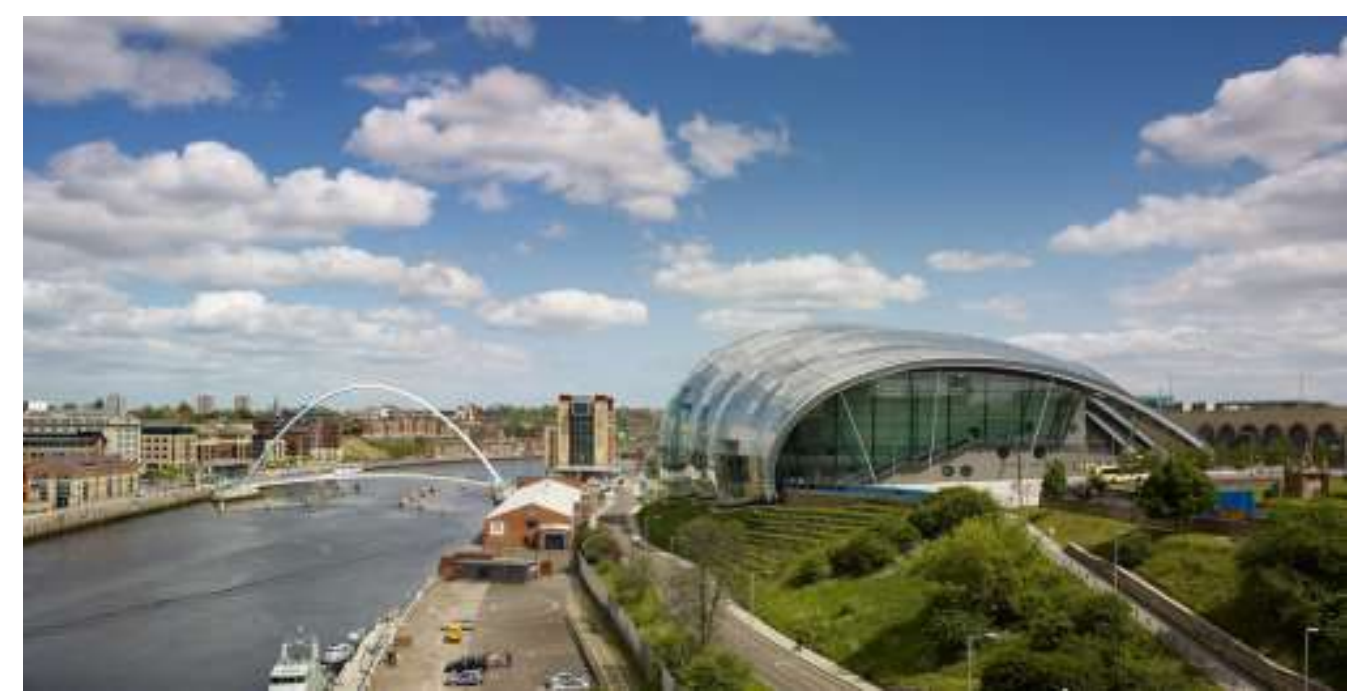

Figure 4. View of Gateshead Quayside

Source: http://www.fosterandpartners.com/projects/the-sage-gateshead/.

\section{Planning Context}

Gateshead quayside played a significant role in the development of the town, while the River Tyne served as the foundation for the development of infrastructure, trade and industrial growth throughout the urban area's history. The industrial revolution in the mid- $18^{\text {th }}$ century gave rise to an economic boom on Tyneside, where transportation of coal, glassworks, ironworks, chemical manufacturing, rope-making and heavy engineering rose. By the end of the 19th century, newly developed infrastructure, particularly the High-Level Bridge, moved traffic away from the quaysides, contributing to the decline of riverbank industries. During the mid- $19^{\text {th }}$ century, rapid population growth resulted in the spread of local workers' housing, eventually becoming overcrowded slums. Gateshead quays became increasingly neglected in the mid-20th century until the 1990s, when regeneration efforts began to be taken, and a number of public projects have since been delivered to revive the quaysides. ${ }^{9}$

9. Newcastle City Council, Gateshead Quays: Masterplan Report (Newcastle upon Tyne: 
Newcastle Gateshead is the dominant economic force in North-East England. The economic development of the North East region is relatively behind that of other parts of the UK. According to Christopher Bailey, one of the priorities for growth in the North East is to encourage the development of small business. ${ }^{10}$ This region has the lowest rate of self-employment of all British regions: 8\%, compared to $15 \%$ in London, and $14.5 \%$ in the South West. Besides the lowest rate in selfemployment, the North East also has fewer people working in the "high-skill and knowledge" group: only $22 \%$ of the population, compared with a $27 \%$ nationwide average. Furthermore, the number of VAT registered businesses in the North East is the lowest in the UK, the proportion of mature businesses is also low, and the expenditure of companies in the North East on research and development is only half of the national average. So in this context, it was claimed that the primary solution to renew this region would be developing the "creative economy", which was seen as a "hybrid sector dealing with creative and cultural products and activities". 11 it is pointed out by Peter Hall that the important trick for urban renewal is to make the city itself creative, rather than focusing on urban tourism and consumption only. ${ }^{12}$ The urban areas of Newcastle Gateshead have the region's major retail destinations, universities and research institutions. ${ }^{13}$ The idea of "culture" as a driver for regeneration in Newcastle Gateshead can be traced to the 1980s, when Gateshead Metropolitan Borough Council made a decision to build Gateshead International Stadium on a brownfield site. Later the Angel of the North was created, followed by Millennium Bridge, BALTIC Centre for Contemporary Art and Sage Gateshead (Figure 5). ${ }^{14}$ All these programmes attract commercial investment for the regeneration of Newcastle Gateshead through the idea of culture and the arts.

The vision for Gateshead quayside was for it to be a place of "international standing", a place that the people of Newcastle and Gateshead would be proud of and that would benefit all people visiting, living and working there. The design of regeneration and development projects was to be of high quality. Design was to take into consideration the need for distinctiveness, inclusiveness, accessibility, attractiveness and usefulness. The area was expected to provide programmes including business and family activities structured around human-scale built forms and unique public spaces in order that a vibrant waterside community would come into being. The area was planned to serve as a linkage, tying together Gateshead's cultural and business quarters, its town centre and Newcastle quayside, being an integral part of all those places, while retaining its own unique identity. ${ }^{15}$

Newcastle City Council, 2010), 23.

10. Christopher Bailey, "Cultural Values and Culture Led Regeneration - the Case of Newcastle-Gateshead," 14th International Conference of the ACEI (Vienna, 2006), 2.

11. Ibid.

12. Peter Hall, "Cultural Wisdom of Gateshead's Music Complex," Regeneration \& Renewal (May 2003): 14.

13. Newcastle City Council, Regeneration in Newcastle upon Tyne (2008).

14. Anthony Sargent and Peter Buchanan, The Sage Gateshead: Foster + Partners (Munich and London: Prestel, 2010): 16.

15. Newcastle City Council, Gateshead Quays, 2010, 12. 


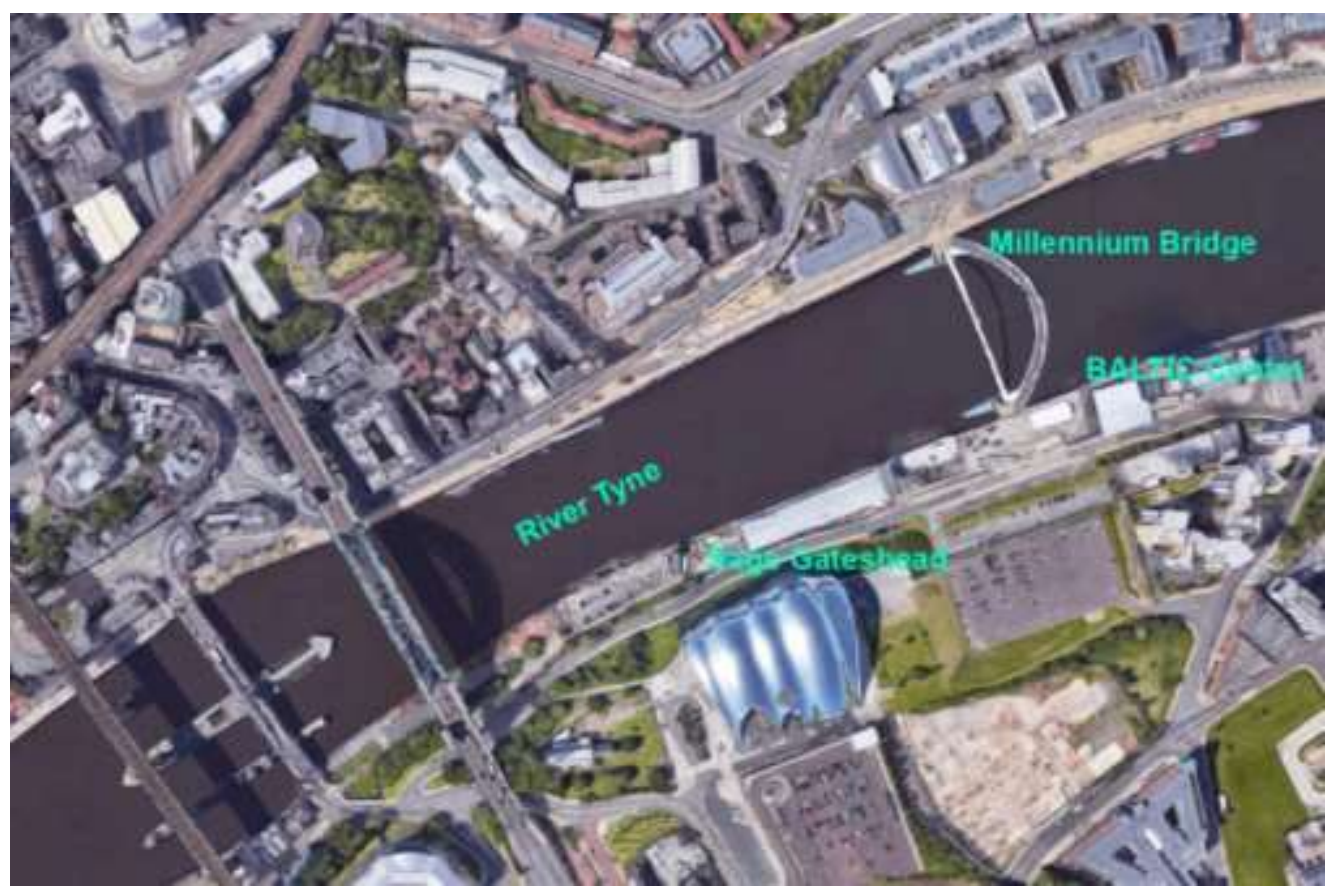

Figure 5. The Urban Context with which Sage Gateshead Engages

Following these visions, Newcastle and Gateshead quayside has experienced a remarkable transformation in recent years. The main creative venues, together with residential developments and two international hotels, were envisaged to bring new life to a place once known for coal and shipping by the implanting of renewed and artistic focal points. ${ }^{16}$ Investments of $£ 138$ million went to the quaysides, aiming to revitalise both physical quality and social life. The revitalisation was centred on and relied on some key cultural and creative projects - the BALTIC Centre for Contemporary Art at a cost of $£ 46$ million, the Sage Gateshead music centre, designed by Foster and Partners at a cost of $£ 70$ million, and Gateshead Millennium Bridge, built for $£ 22$ million. These contemporary projects combined as a cluster in order to redefine an area which used to be the mark of prosperity of the industrial age.

The BALTIC was transformed from a 1940s grain warehouse and is now a contemporary arts centre overlooking the River Tyne which opened to public in 2004. The Sage Gateshead, opened in 2005, was not planned purely as a building for performance and public entertainment. It would also be the place where local organisations were based - including the Northern Sinfonia, Folkworks and a music education centre. The Millennium Bridge, the first tilting bridge in the world, linking Newcastle and Gateshead over the River Tyne was opened in 2001.

Nowadays, The BALTIC contemporary art gallery and Sage Gateshead music centre still function as two attractor poles in the mixed-used development on Gateshead quayside. ${ }^{17}$ There is a loop of attraction across both banks of the river. This runs from the bars and restaurants of Newcastle quayside, passes across

16. Steven Miles, “'Our Tyne': Iconic Regeneration and the Revitalisation of Identity in Newcastle Gateshead," Urban Studies 42, no. 5/6 (2005): 916-17.

17. Sargent and Buchanan, The Sage Gateshead, 2010, 16. 
Millennium Bridge, connecting the two banks, arrives at the BALTIC gallery, then climbs up to Sage Gateshead, and finally descends to the Swing Bridge and reconnects with Newcastle quayside. Therefore, the collaboration of a cluster of creative and pleasure programmes around the river banks means that Newcastle Gateshead quayside can be portrayed as an exemplar of projects aimed at urban revitalisation through cultural production. ${ }^{18}$ It was also suggested that due to the development of large numbers of cultural programmes, the cultural production in Newcastle Gateshead quayside would bring new-born creative focus and confidence which could lead to the revitalisation of regional cultural identities. Identities such as these are effective resistance against the homogenisation of globalism. $^{19}$

Site context and regeneration visions provide architects with meaningful references to draw on for building design. These references include the expectations for the building - to be attractive, distinctive, cultural, international, useful, public and vibrant, as well as social expectations of a place that is a unique and functional public space; to provide a human-scale built form for all activities; and to be a place for all people who work, live and visit - that is, social inclusion. These ideas will be taken as design references and guidance for architects and will be embodied in building forms.

\section{Design Concept}

The architect's concept was to be created based on the vision of establishing Tyneside, as an international arts destination, as well as filling a gap on the map for a major music venue in North-East England. The \$122 million (approximately $£ 74$ million) Sage Gateshead was conceived in 1997 after Gateshead Council held a competition for the contract for the design of a concert hall complex. It has been subsidized by an $\$ 83$ million ( $£ 51$ million) grant from the Arts Council England, grants from One North East, the regional development agency and the European Regional Development Fund, plus a \$10.5 million ( $£ 6.4$ million) donation from a local software company. ${ }^{20}$

Of the 100 architects who registered for the competition, 12 were asked to do concept sketches. Six international firms went on to the shortlist and they were asked to provide detailed schemes, and finally Foster and Partners won the competition. $^{21}$ The Foster team was led by Spencer de Grey, Robin Partington and Jason Flanagan, with Arup Acoustics, led by Raj Patel and Bob Essert. This is the first performing arts building designed by Foster and Partners. Their building concepts followed planning visions, which were to make the building a place with a diverse and inclusive social mix, to take cultural activities as a stimulus for

18. Peter Van der Graaf, Out of Place? Emotional Ties to the Neighbourhood in Urban Renewal in the Netherlands and the United Kingdom (PhD thesis, University of Amsterdam, 2008), 232.

19. Steven Miles, Newcastle Gateshead Quayside: Cultural Investment and Identities of Resistance (2004).

20. Suzanne Stephens, "The Sage Gateshead, England," Architectural Record 193, no. 8 (2005): 106.

21. Ibid. 
spatial vitality, and to envisage the building as functioning for all people rather than merely acting as a visual icon for visitors. ${ }^{22}$ Foster and Partners believed that art is an essential part of urban life. Art can inspire and educate people and can also be a force for the revitalisation of a city. ${ }^{23}$

Sage Gateshead music centre includes three main performance halls, each with specific spatial and acoustic criteria. Besides being a concert hall, it is also home to a music education centre for local residents. A multi-functional concourse links the three halls together, serving as a public street overlooking the waterfront. The most eye-catching element is the curving silver shell wrapping up the three halls. By proposing a public and informal atmosphere with the help of river views, architects envisaged Sage Gateshead to be one of the city's great new social spaces. $^{24}$

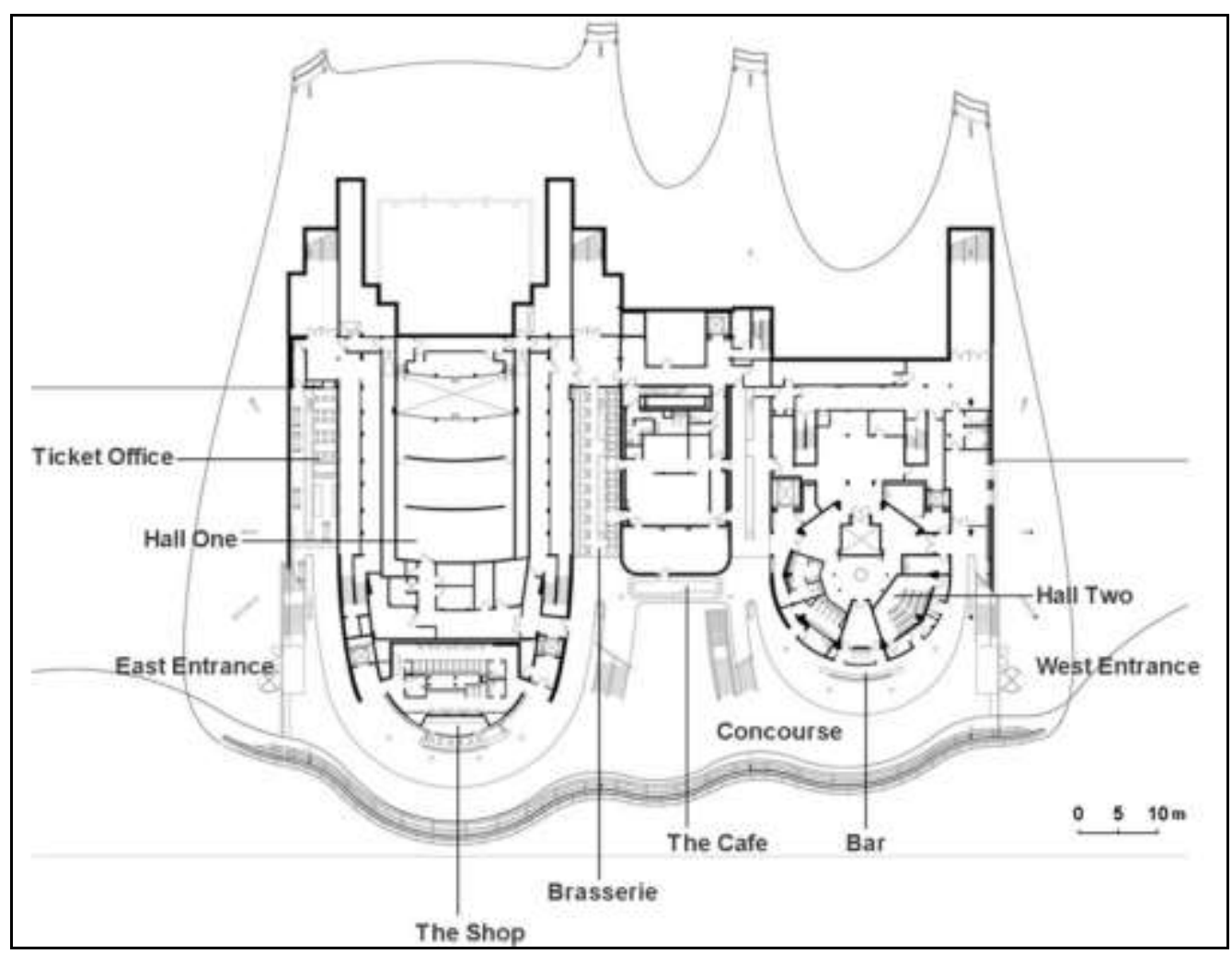

Figure 6. Concourse Level Plan

Source: http://www.fosterandpartners.com/projects/the-sage-gateshead/.

22. Sargent and Buchanan, The Sage Gateshead, 2010, 14.

23. Mark A. Newman, "Urban Living Room - The Sage Gateshead Gives New Meaning to the Term 'Mixed Use'," Entertainment Design 39, no. 7 (2005): 23.

24. Chris Abel and David Jenkins, Norman Foster: Works 5 (Munich and London: Prestel, 2009), 219. 


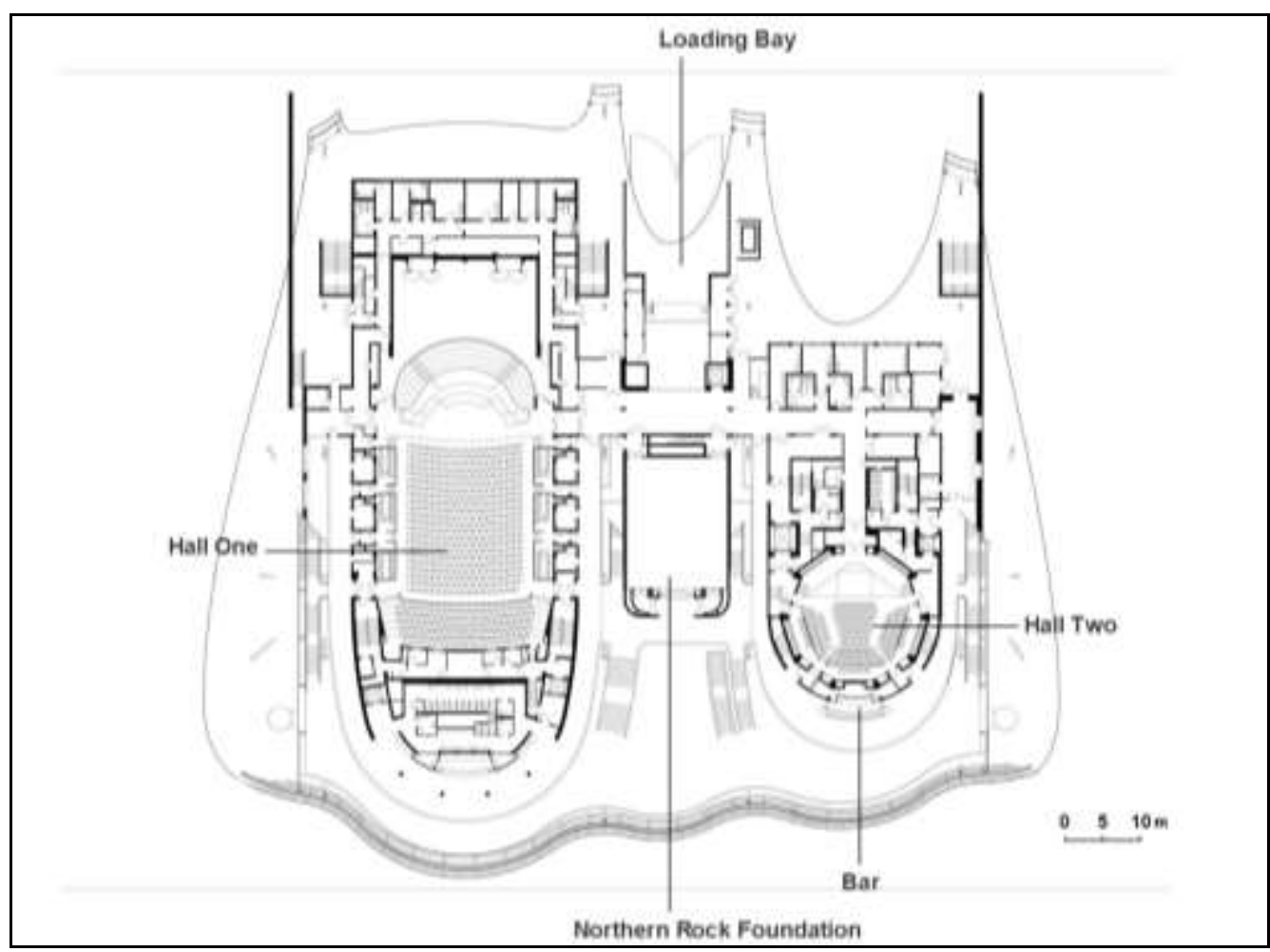

Figure 7. Level 1 Plan

Source: http://www.fosterandpartners.com/projects/the-sage-gateshead/.

The key concept the Foster team created was to make the building an "Urban Living Room". Foremost here was that the project should not only contribute to the urban regeneration of the quayside by creating a cultural symbol for the sake of the city's image, but should also offer an "Urban Living Room" for the local community to enjoy and share music. ${ }^{25}$ Sage Gateshead was planned to be an internal public realm where people from different social groups could meet. This living room is equally accessible to everyone through the various activities taking place in it. The living room focuses on real life. The identity of the living room is flexible and can be changed according to who is using the space.

The concept of building an "Urban Living Room" was materialised into the most significant physical space in the building - the concourse (Figure 6). It can be seen from architect's conceptual diagrams that the heart of the building is the concourse, a place for welcoming, relaxing, accessing halls and music classrooms or waiting for concerts, as well as a splendid place for river viewing. This eventmixing machine aims to provoke social encounter and interaction, thus providing a sense of involvement and harmony and a wide range of inclusion. ${ }^{26}$ Hence, the meeting of the enormous range of different activities is considered to be what the building works for. This concept largely echoes the regeneration vision of creating a place for all people and making public space both unique and vibrant. Sage Gateshead also responds to Sennett's claim that the city should be the place where

25. Newman, "Urban Living Room," 2005, 23.

26. Sargent and Buchanan, The Sage Gateshead, 2010, 15. 
strangers meet.

Besides the concourse, the concept of social inclusion was also reflected in the design of the concert halls. There are two main halls. Stairs on either side of the hall climb straight up to the galleries from the concourse. Hall One is a large concert hall for the resident orchestra, Northern Sinfonia, which had long lacked a home, as well as for visiting orchestras and other larger-scale musical groups. The other hall is smaller and more intimate for chamber music, folk, jazz and other intimate performance (Figure 7). There is also a rehearsal room which has multifunctional use for performances, school music showcases and full orchestra rehearsals. ${ }^{27}$ Each hall was designed as a separate enclosure, but the windswept nature of the site suggested a shelter "shrink-wrapped" around the entire building. ${ }^{28}$ Flexibility and high quality are priorities so as to attract better performances and more other uses, such as conferences and recording sessions. Education and community participation are also priorities. Education takes place not only in the education centre, but also in the form of performance in the concert halls. The centre seeks to encourage everybody to engage in music making. The concerns of flexibility and public participation aim to achieve more social involvement and a broader mix of social groups and activities, so that more people benefit from the building and it functions better as an "Urban Living Room.", 29

Hall One is a classic shoebox hall, 45 metres long, 24 metres wide and 21 metres high, and seating 1,700. The flexibility of Hall One is achieved through a number of devices. It has six moveable ceiling panels and acoustically absorbent curtains. The height can be adjusted by raising and lowering ceiling panels between 10 and 21 metres, so the volume of the hall and the sound reflections can be adjusted and it is easily made to suit any type of music and speech. The stage is also moveable and adjustable, with a basic platform that can be rolled forwards and backwards, and has a slight acoustic resonance to help the sound work and enable musicians to feel their peers' playing. The stage can be set up to suit the size of the performance group by adding or subtracting smaller platforms of different sizes and shapes, so that musicians can see each other and can be seen by the audience. Stage flexibility, therefore, is devoted to enhancing the integration between musicians, and between musicians and audience, as well as the participation of the audience.

Hall Two is very different from Hall One in character. It is a tall, ten-sided prism in shape. The main level has a flat floor and is surrounded by two galleries. Walls are decorated with red-stained wood, warm and passionate, bringing an atmosphere of a jazz club or a pub theatre. Hall Two looks more intense and intimate than Hall One, which serves to create better interaction between musicians and audience. The principle of flexibility and wider involvement is also considered in the design of Hall Two. The main level has retractable seating and its decagonal shape allows it to be arranged in various ways, such as with a stage on one side or in the centre (Figure 8 ). ${ }^{30}$ Hall Two is programmed to be used for a

\footnotetext{
27. Ibid, 19.

28. Foster and Partners, "The Sage Gateshead UK 1997-2004."

29. Sargent and Buchanan, The Sage Gateshead, 2010, 23.

30. Ibid, 26.
} 
wide range of folk and world music, jazz, contemporary dance, opera, theatre-inthe-round, chamber music and broadcast recordings. At the same time, the architects also considered how music would be performed in the future, and thus they left room to accommodate avant-garde music in three dimensions. ${ }^{31} \mathrm{By}$ designing an intimate space, moveable seating and stages, and leaving room for future change, social interaction is significantly increased, as more activities are expected to be attracted to and take place in Hall Two.

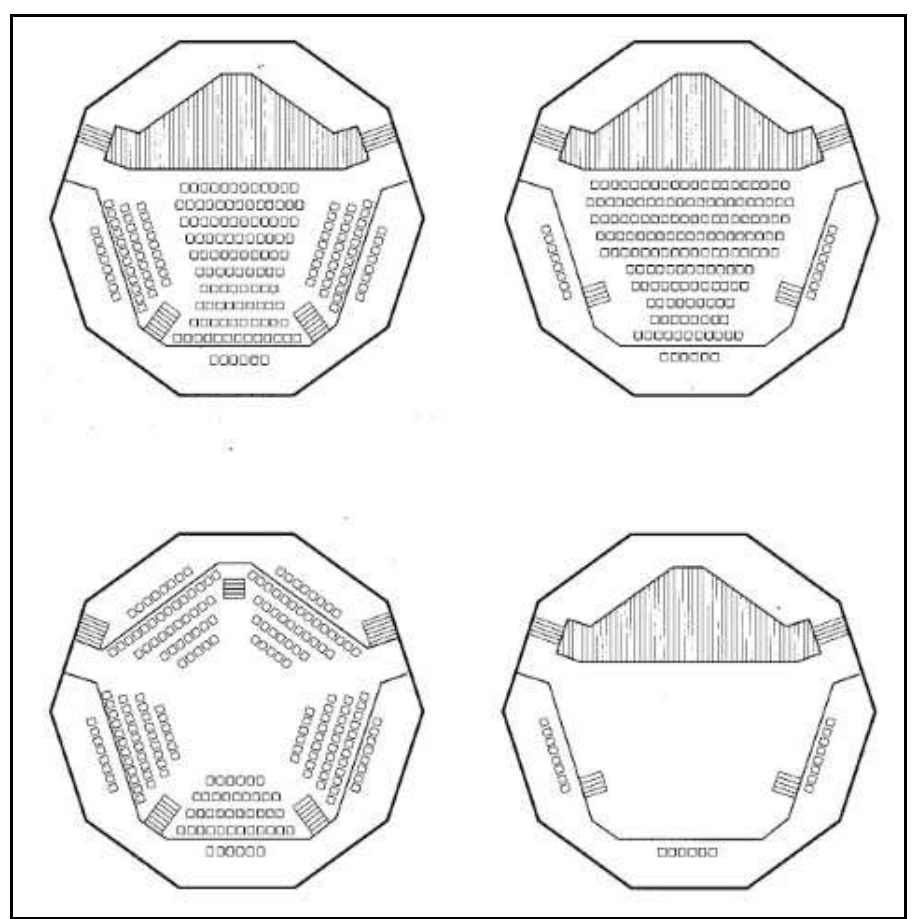

Figure 8. The Main Level of Hall Two can be arranged in Various Ways Source: The Sage Gateshead: Foster + Partners, p. 21.

The rehearsal room - the Northern Rock Foundation Hall - sits between Hall One and Hall Two but is set slightly further back. ${ }^{32}$ It is a simple rectangle in shape, with shoebox proportions. As it needed to function for orchestra rehearsal, it was designed with similar natural acoustics to Hall One so that musicians can adapt to acoustic conditions easily before moving to the larger performance hall. Flexibility has been applied here as well. It has a flat floor without any fixed furniture. Seats and stage can be set up according to what the room will be used for, such as orchestra rehearsal, chorus rehearsal, school music showcase, solo piano performance, dance festival, banquets and exhibitions. It can accommodate 300 audience members at maximum capacity. When the room is in use, the big window overlooking the concourse creates a visual connection between the musicians and people outside. If the doors are open, the rehearsal room becomes a semi-public space.

The public viewing box in Hall One works in the same way, in that it

31. Newman, "Urban Living Room,” 2005, 22.

32. Ibid, 27. 
creates the chance for the public to see rehearsals for free. Openness and transparency reduce the distance between musicians and the public and allow the public to get closer to the music, enhancing people's sense that music is not some mysterious job only for musicians but something in which everyone can be involved and from which anyone can benefit, through various kinds of engagement.

There is a loading bay behind the rehearsal room. The bay gives access to the rehearsal space, leading in one direction to Hall One and in the opposite direction to Hall Two, which makes it a cross-axial route. Large instruments and other equipment can be easily delivered to any hall or be moved between them through this loading bay. A lift on one side of the bay serves for deliveries to the kitchens of the brasserie and cafe on the concourse level. In addition, there is a "green room" at the far west of the building serving as rest space for musicians when they are not on stage. There are also dressing rooms behind the cross-axial route. However, there are few backstage facilities other than these. In planning the building in this way, the architects aimed to encourage musicians to use public spaces, such as the bars at the galleries outside the halls and the cafe in the concourse, in order to get them mingle with the public.

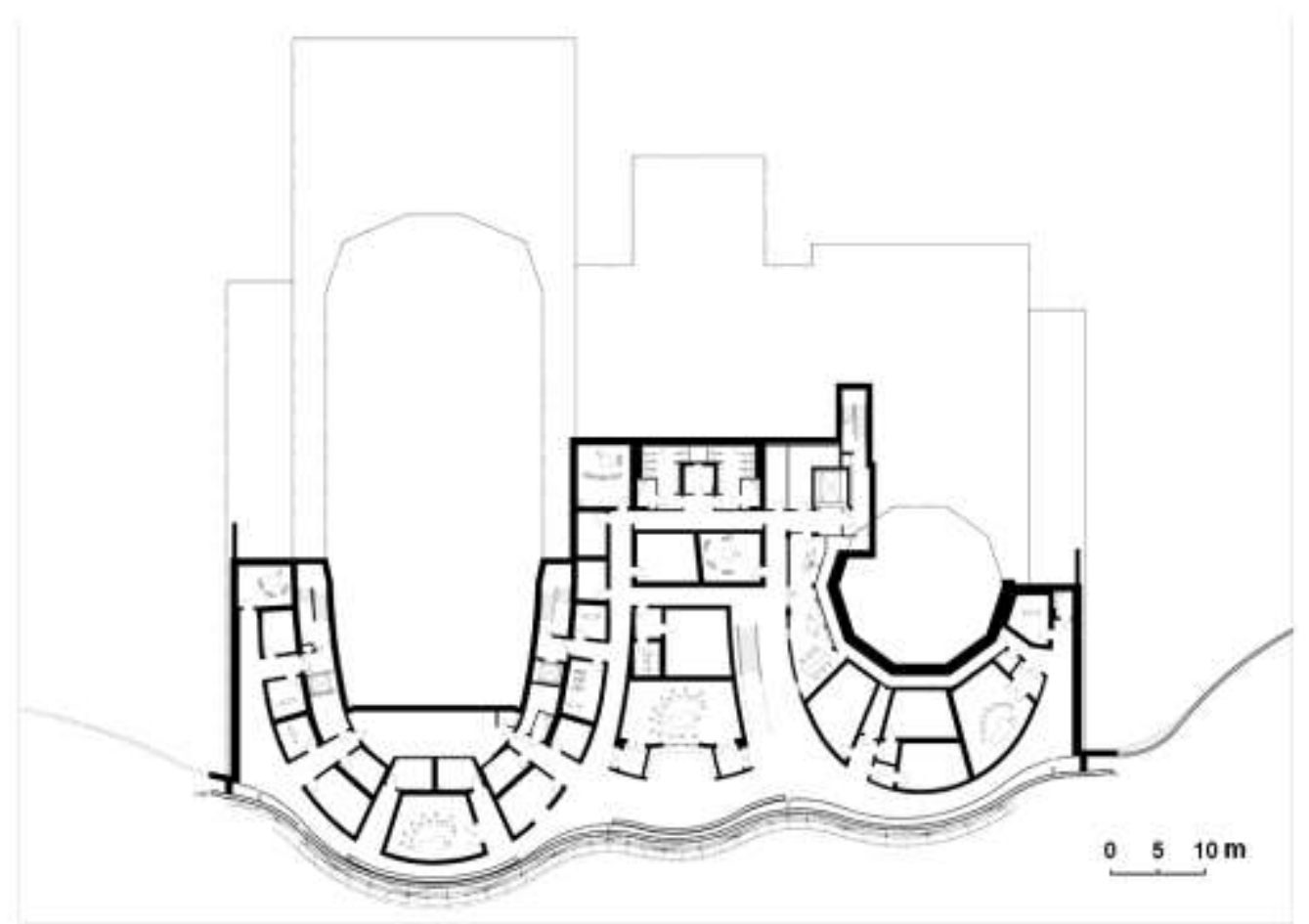

Figure 9. Level - 1 Plan: The Music Education Centre

Source: http://www.fosterandpartners.com/projects/the-sage-gateshead/.

The music education centre was planned underneath the concourse level, where 26 practice rooms with non-rectangular shapes are now found, filling the space between the foundation walls of the halls and the curved surface (Figure 9). This gives rise to a panoramic view towards the River Tyne through the 
curving glass curtain. ${ }^{33}$ The music education centre makes the building not only a concert venue for professional musicians, but a real music-making and music-playing place for anyone, young or old, working or retired. ${ }^{34}$ The music education centre is also semi-public: people can access it from the concourse, walk along the galleries and watch music being played inside practice rooms through their windows. Hence the music education centre is also a place where people from various social groups meet and enjoy music, again corresponding to the concept of achieving a wider social mix.

The architects envisaged Sage Gateshead as an efficient working building with warm and elegant public space. Rehearsal and musical practice are visible; musicians are encouraged to stretch themselves into public zones, audiences are surprised to find they are connected easily with artists. Everything is planned in such a way as to try to ensure that the functioning of Sage Gateshead is transparent. It is a practical and legible working machine, and it encourages everybody to be engaged in social life through the joy of music. The architects were aiming to fulfil the brief as well as to achieve the social meanings which Newcastle Gateshead required - to be culturally attractive, to create a social mix and a wider range of involvement, and to be a home of music for the whole public. At the same time, the softly gleaming and sinuous surface, large-scale volume and eye-catching shape guaranteed that Sage Gateshead would be iconic. It would deliver both functional and iconic features and satisfy the needs of urban regeneration.

\section{Everyday Life at Sage Gateshead}

City planners had grand ambitions to make the building a city icon to express "international standing", as well as to enhance the artistic status and distinctiveness of Tyneside. Besides those planning visions, social inclusion and diversity were significant considerations in the city revival plan, in order to make a useful and vibrant place, beneficial to all people visiting, living and working nearby. Following the planning prospects, the architects proposed the concept of an "Urban Living Room" for Sage Gateshead, aiming to contribute to public participation in shared common spaces instead of promoting the city's image as a cultural symbol only. After the building came into use, the programmes and activities happening in the space might answer the question of whether or not Sage Gateshead has already become an Urban Living Room that corresponds to the architects' concept and the planning expectations of social inclusion and diversity.

Management Goals

Sage Gateshead and all of its regional, national and international work is managed and programmed by North Music Trust. The mission of Sage Gateshead's performance, learning and participation is "to entertain, involve

33. Ibid, 29.

34. Hall, "Cultural Wisdom,” 2003, 14. 
and inspire each and every person" through "engagement with outstanding music and creative events".

To achieve its mission, North Music Trust has established five main agencies running events and programmes for participants and audience. ${ }^{35}$ The music education centre offers courses, classes, workshops and summer schools for people from pre-birth to over 90, from first note to higher education, across all kinds of music, serving about 2,000 people each week. Many of the choirs, orchestras, bands and ensembles perform on stages at Sage Gateshead, around the UK and beyond. The concert halls are homes of music in the North East with an audience of 220,000 people each year. Concerts held in the two concert halls range from the world's most famous artists to the next big thing, from choirs to dance, and from jazz to classics. Royal Northern Sinfonia is permanently accommodated at Sage Gateshead. Made up of professional musicians who play on their own stages and around the world, the Sinfonia is the leading chamber orchestra in the North East and the only full-time one in the UK. ${ }^{36}$ Folkworks is an organisation developing and encouraging interest and involvement in traditional music, song and dance, as a means to nurture young artists, and expand audiences and participants. Sage Gateshead is the leader in community involvement programmes. Music is used to develop skills and life chances, strengthen community relations and improve health and well-being across the North East and across ages, with the help of health, education and social care partners. In addition, Sage Gateshead possesses venues to let for events from conferences to weddings, so as to contribute economic value to the region. ${ }^{37}$ These activities run by Sage Gateshead work together collaboratively; for example, the concert events sometimes staged by those involved in Folkworks contribute to bonding people together, and so to strengthen community cohesion.

According to Sage Gateshead, over the first few years of management of its programmes, the learning and training programmes grew steadily, so in 2010 it took the next step of drawing together the "Artistic Principles" that underpin all of its artistic programmes. The principles give detailed guidance on the diversity of the programme to enable more social groups to participate, by programming more new and a wider range of activities targeted at different ages and stages, as well as by integrating learning, participation, performance and other activities taking place in the building. The principles also seek to build demand for and engagement in music by ensuring close collaboration between programmes and promotional teams in listening to audience and participant feedback, by analysis of market data, and by working closely with communities. The principles are also concerned with a wide range of partnerships. Partners could include local authorities, educational institutions, independent music promoters, community organisations and other venues. $^{38}$

At management level, the planning prospects and architectural concept have been taken into account and effort has been made to achieve them. Equality and

35. Sage Gateshead, Annual Review/September 2014-August 2015 (2015).

36. Ibid.

37. Ibid.

38. Sage Gateshead, Artistic Principles (2016). 
diversity are goals embedded in the organisation of programmes. North Music Trust is committed to implementing equality and diversity by ensuring that "decision making about our workforce is based on skills, abilities, potential and experience", by designing activities according to "the needs of the communities" that it serves, and by providing entertainment to encourage as wide an audience as possible to be involved. ${ }^{39}$ The commitment to broad social inclusion that North Music Trust provides is supported by trained staff, so as to ensure that the planning prospects and architectural concept are thoroughly realised in actual use.

What is going on in the Building?

Two entrances at the west and east side of the building welcome the public from several directions. Accessing the building through the east entrance and passing the ticket office, there is a shop on the concourse level right underneath the north gallery at the back of Hall One. The shop offers many cultural products, including architectural books detailing the concept and design of Sage Gateshead, visitors' guidebooks to Newcastle and Gateshead, collections of places of interest across the region, music cultural handbooks, music-learning materials and instruments, as well as various souvenirs featuring the Sage Gateshead logo. These cultural products are produced by Sage Gateshead under the theme of music and the Sage Gateshead brand in the form of books, instruments, postcards, collections, mugs, pencils and children's toys. These products in turn reinforce the cultural identity of Sage Gateshead, because they help to further enhance Sage Gateshead's iconic status and its role in music making.

There is a cafe and a brasserie below the Northern Rock Foundation Hall on the concourse level (Figure 10). There are also four bars in the building. One of them is right below the north gallery of Hall Two. Visitors can use these without having to buy concert tickets. Tables and chairs are set in front of the cafe in the middle of concourse and along the concourse edge opposite the bar. When there is no special event taking place, there are usually ten to fifteen people sitting, eating or chatting in groups. Some participants walk across the concourse in a hurry from one of the entrances to their music-learning studios. Some families with babies come to join family workshops. Other visitors wander more slowly over the concourse and sometimes stop to have a seat and a cup of tea. Some people like to stand at the edge of the concourse, looking towards the river and Newcastle city through the glazed enveloping roof canopy. Some who work nearby just have a relaxing walk from one entrance to another across the concourse during their lunch break. The concourse is usually busy and lively.

39. Sage Gateshead, Equality and Diversity (2016). 


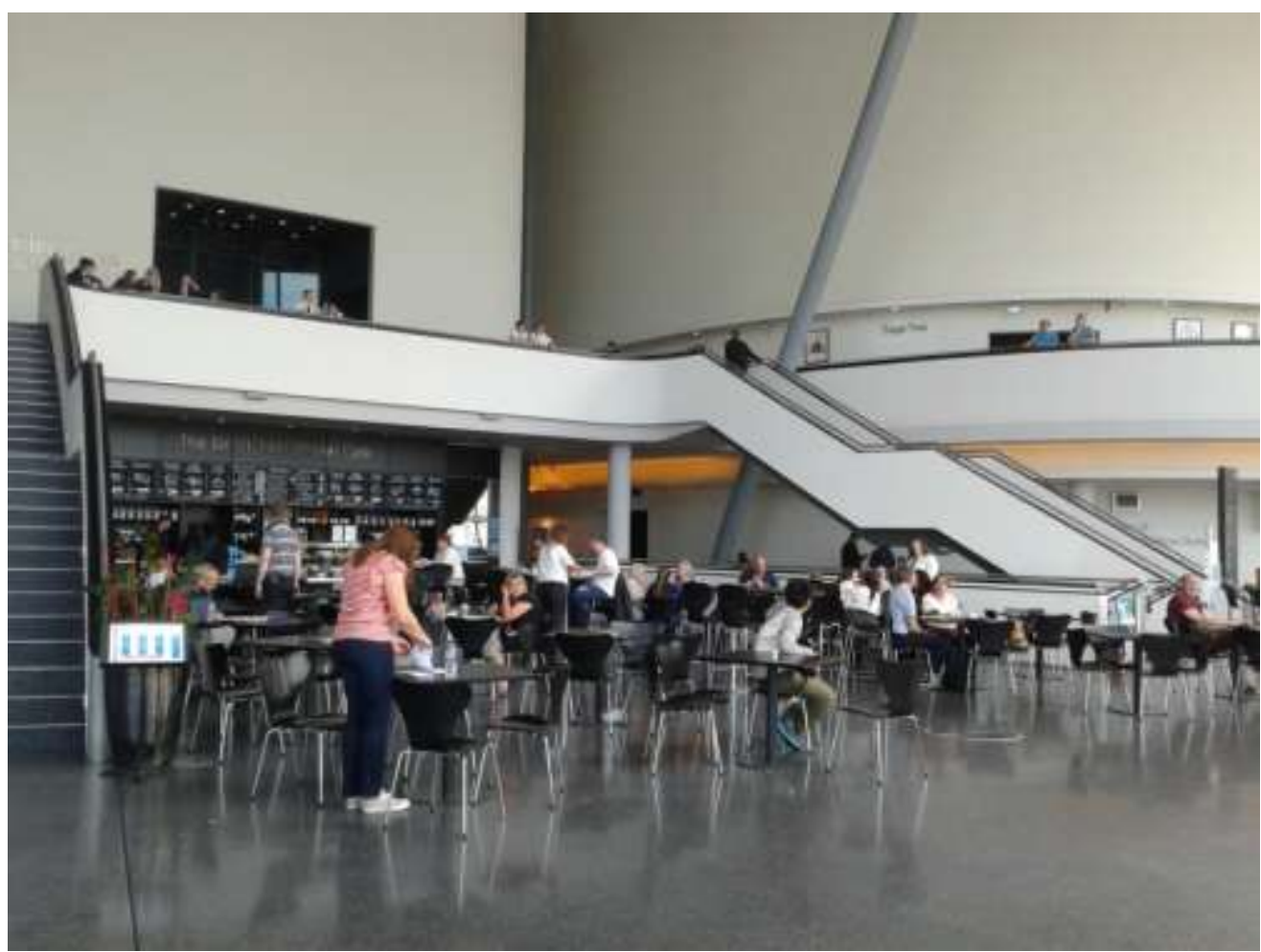

Figure 10. The Cafe

Sage Gateshead offers room for people who love performing and want to showcase their musical talent in front of an audience on the concourse stage (Figure 11). A slot to perform on the concourse can be booked through the Sage Gateshead website. This opportunity Sage Gateshead provides is for a wide range of music lovers to perform live, including emerging artists, community ensembles and school groups. As the concourse is meant to be a public living room and it is already a vibrant place, these live performances help to animate it further. So occasionally there are choirs, bands, or a small orchestra performing in the centre of the concourse, and the café, as well as the galleries outside the halls become temporary watching stands, thereby spontaneously converting the spaces between the halls and enveloping roof canopy into a temporary harmonious performance space. People who are sitting in the cafe and walking through concourse become a temporary audience. River Tyne and Newcastle city becomes the backdrop to the concourse stage, reminiscent of Greek open-air theatres with ocean views as their backdrop. 


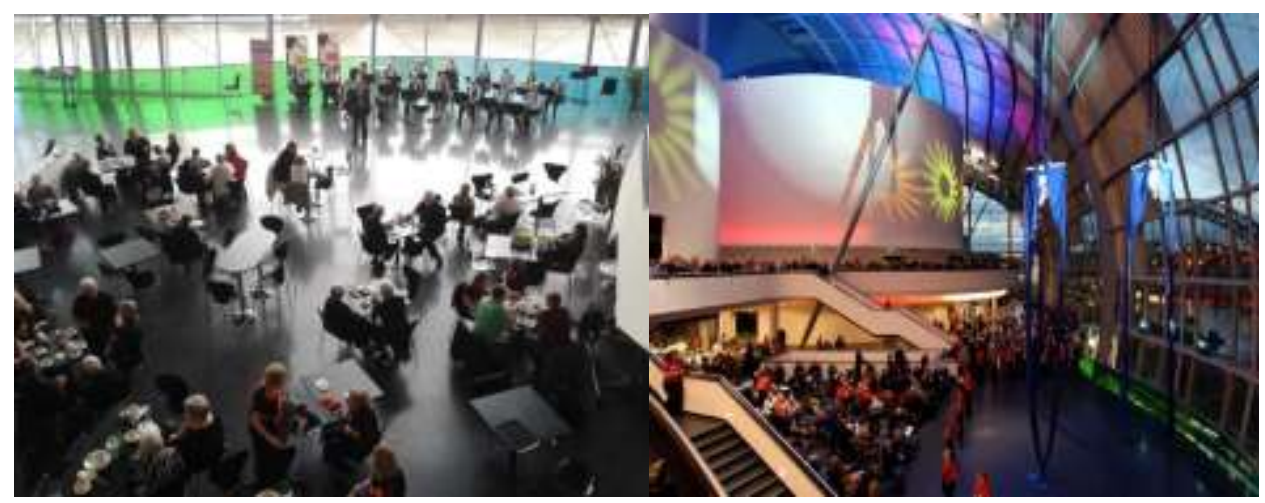

Figure 11. Performance in the Concourse Space

The question is what gives the concourse space this potential to become a live theatre or performance space. The major reason is that the concourse space, including the cafe and the gallery areas, corresponds to the typology of a theatre. The basic spatial typology of a theatre is that it consists of a stage and seating areas, and that there is a strong relationship of interaction between the activities of performing and watching. The space at the centre of the concourse acts as a stage, while the cafe acts as the stalls and the overhanging galleries of the upper level as the balcony. The watching area embraces the performing area, representing a spatial form with a strong relationship between performing and watching. Any prototype is about one certain spatial morphology in which relevant activities take place. There is a prototype of schools and activities associated with schools, there is a prototype of hospitals and activities associated with hospitals, and there is a prototype of theatres where the performing/watching activities can take place. The concourse space provides pre-conditions for performing/watching activities because it conforms to the basic principle of the typology of a theatre, thereby possessing the potential to accommodate theatre activities. Therefore, when there is a live performance happening on the concourse, people will gather together, some will sit at or stand near the cafe, some will watch from the upper-level galleries, and thus the relationship of performing and watching is spontaneously built and the sense of a live theatre is generated (Figure 12).

There are performances in concert halls and on the concourse for all tastes - popular, jazz, world, classical, dance, brass bands, experimental, folk and traditional, and so on. Both domestic and international musicians, from Europe, America, and other parts of the world, and both world-class musicians and the centre's own training bands - all can perform in Sage Gateshead. Performances are at different times of day - mornings, lunchtimes, evenings and late at night. Audiences are able to find any performance according to their preferences and free time. 


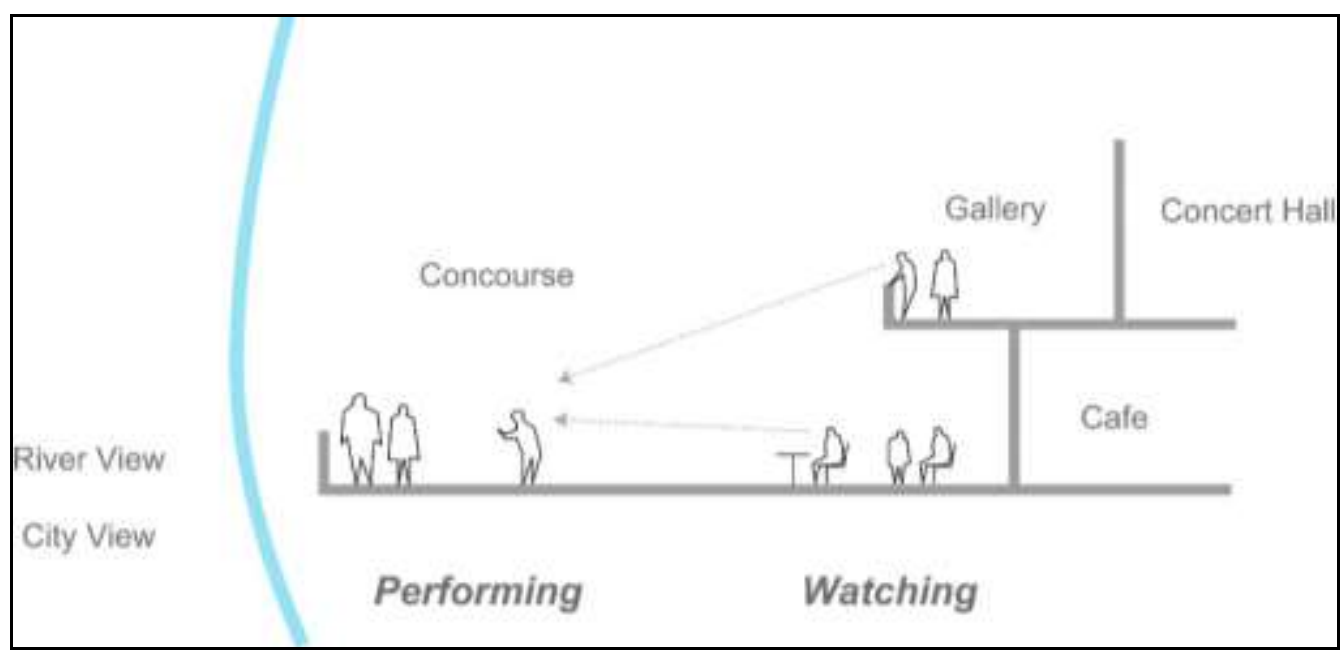

Figure 12. The Concourse Space Working as a Theatre

Before the start of a concert, especially a big concert held in Hall One, the concourse will become extremely crowded and lively (Figure 13). People use the concourse space as a waiting room. Some people prefer to have a drink in the bar, some like to have a brief meal in brasserie or the cafe, some stand at the edge of concourse and enjoy the river view, while some walk in and around the building. After the concert begins, the concourse will gradually return to normal.

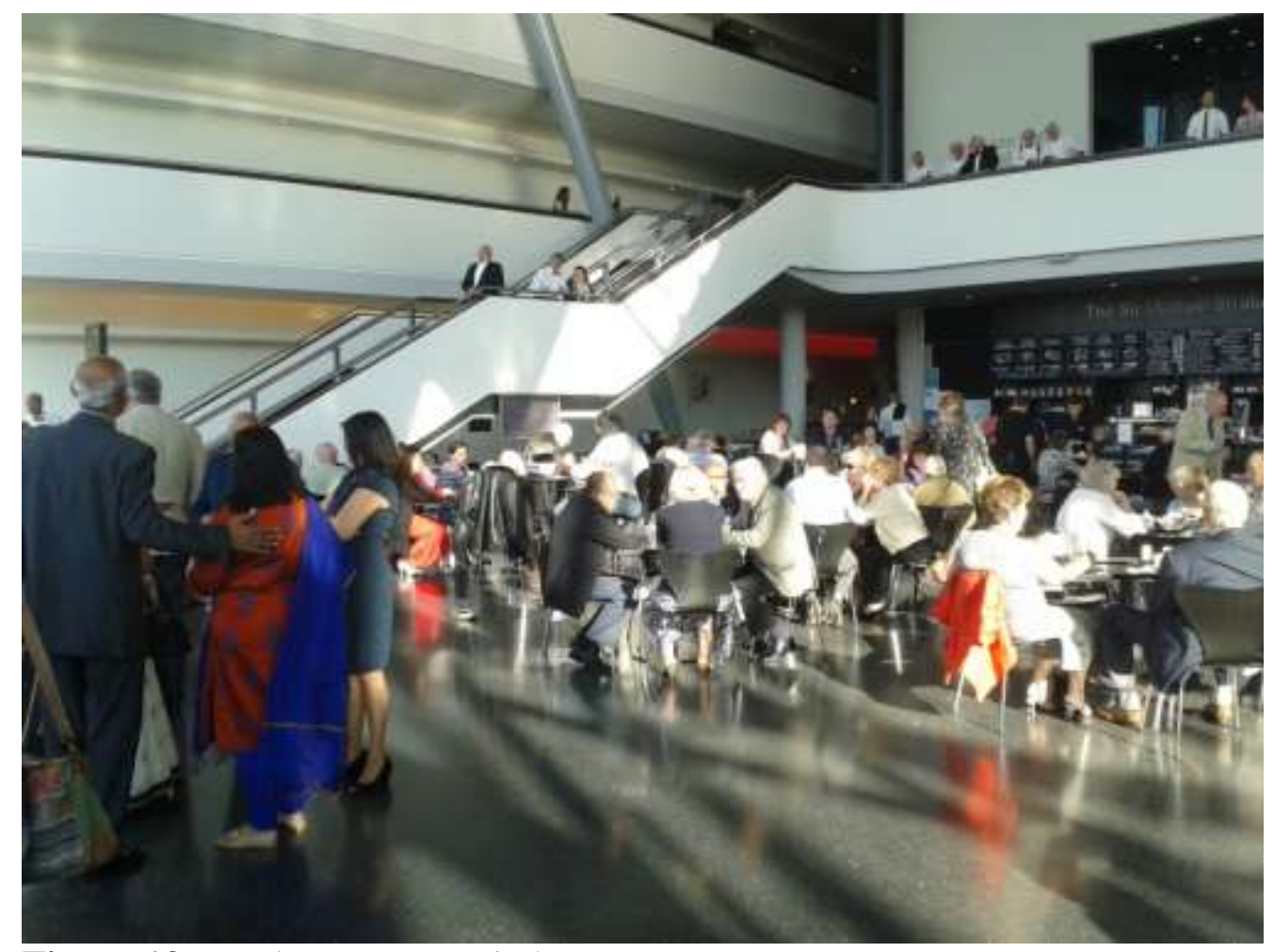

Figure 13. Lively Concourse before Concert 
Usually there is a 20-minute break in the middle of a concert. During breaks audiences are encouraged to come to the galleries outside the halls and enjoy the bars there. Musicians are also encouraged to come and relax on the galleries with drinks and conversation. Therefore, during a break it is possible for audiences and musicians to meet and share their experience of the music. This opportunity offered to both audiences and musicians reduces the distance between them - audiences come into close contact with musicians, while musicians can get face-to-face feedback from audiences. The mix of audiences and musicians also helps to enhance the sense of an "Urban Living Room", because the mix enables more social encounters to occur between diverse groups of people.

Sometimes when there is live music being performed on the concourse stage during a concert break, it is very interesting to see interactions taking place between the two activities. People who are gathering around gallery bars become a temporary audience for the concourse performance during the concert break, and the liveliness in the building is doubled immediately. People who are drinking and chatting on the gallery level unexpectedly have an extra chance to enjoy live music, and the concourse performance gains an additional audience for 20 minutes. People who come to the galleries are automatically entering into a theatre space, as the concourse space coincides with the typology of theatres and the potential to serve as a theatre. So the people gathered in the galleries or at the bars unconsciously take on the role of audience for the concourse show. In this way the performing-watching relationship in the concourse space is reinforced and the identity of the building as an "Urban Living Room" is made more legible during concert breaks.

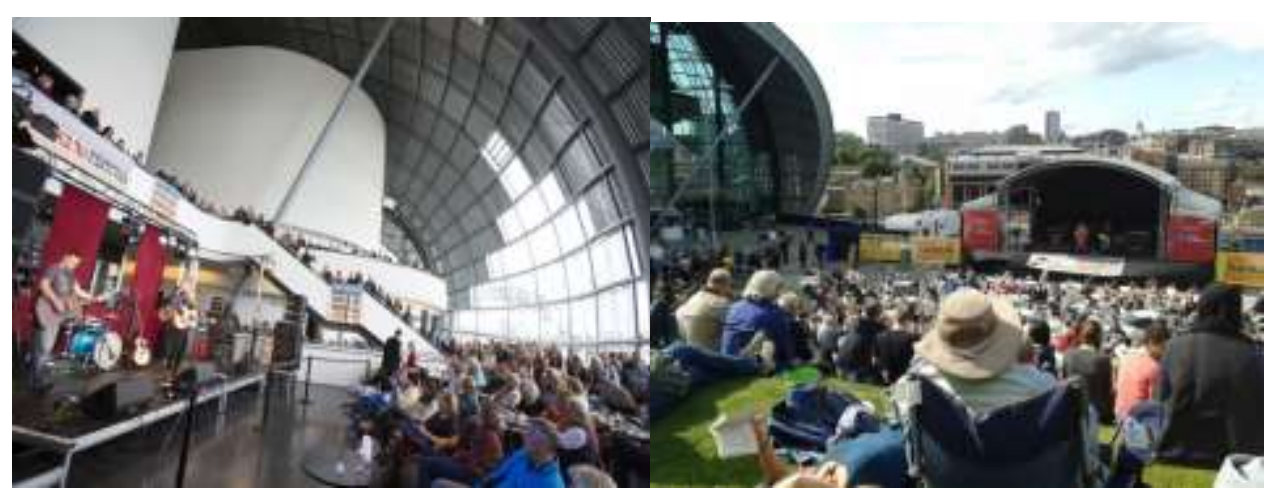

Figure 12. Open-Air Free Stage Performance during SummerTyne Americana Festival 
Vol. 5, No. $1 \quad$ Ye: The Pragmatic Role of Iconic Buildings in Promoting Social...

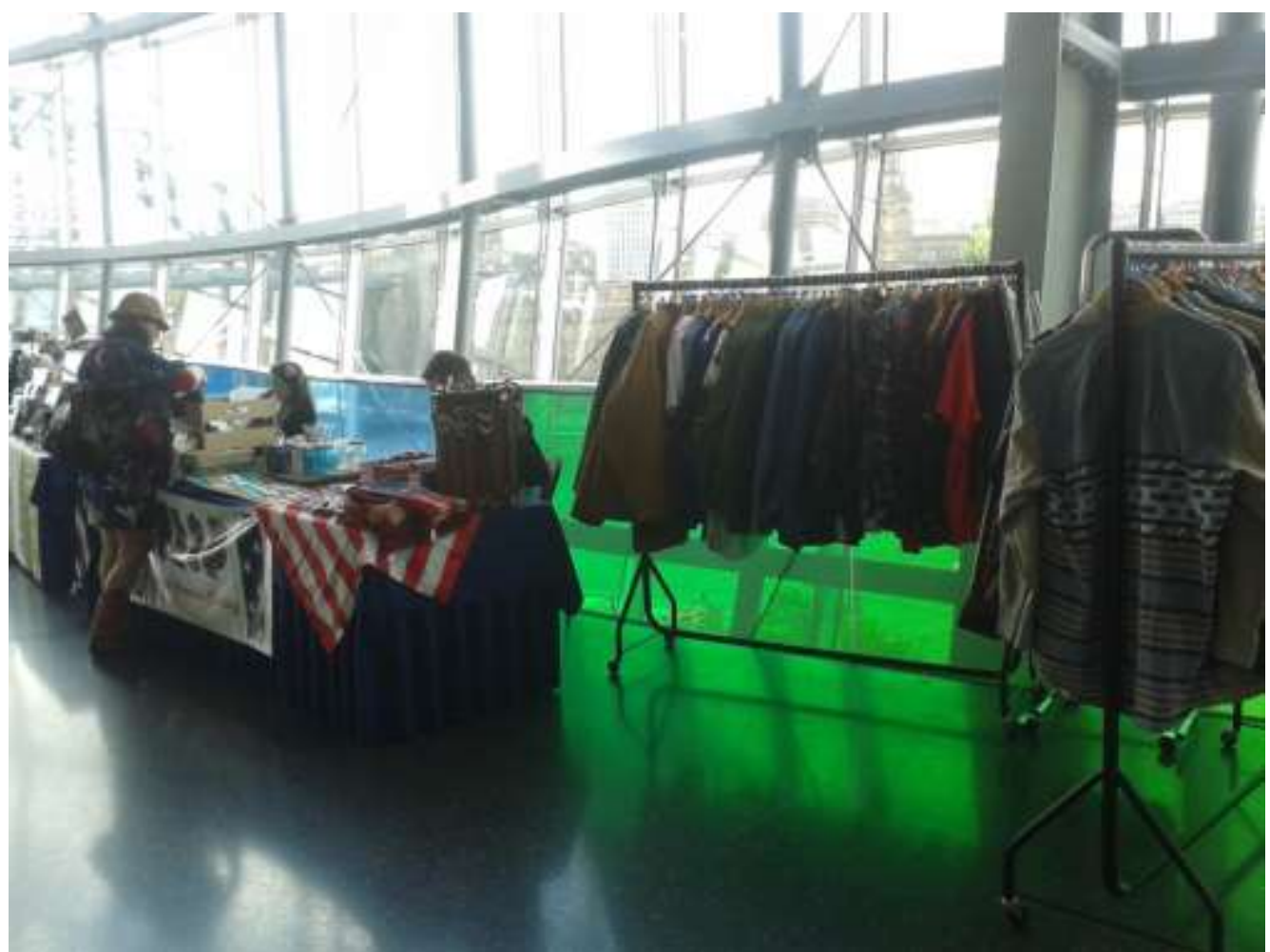

Figure 13. American Cultural Products Stalls

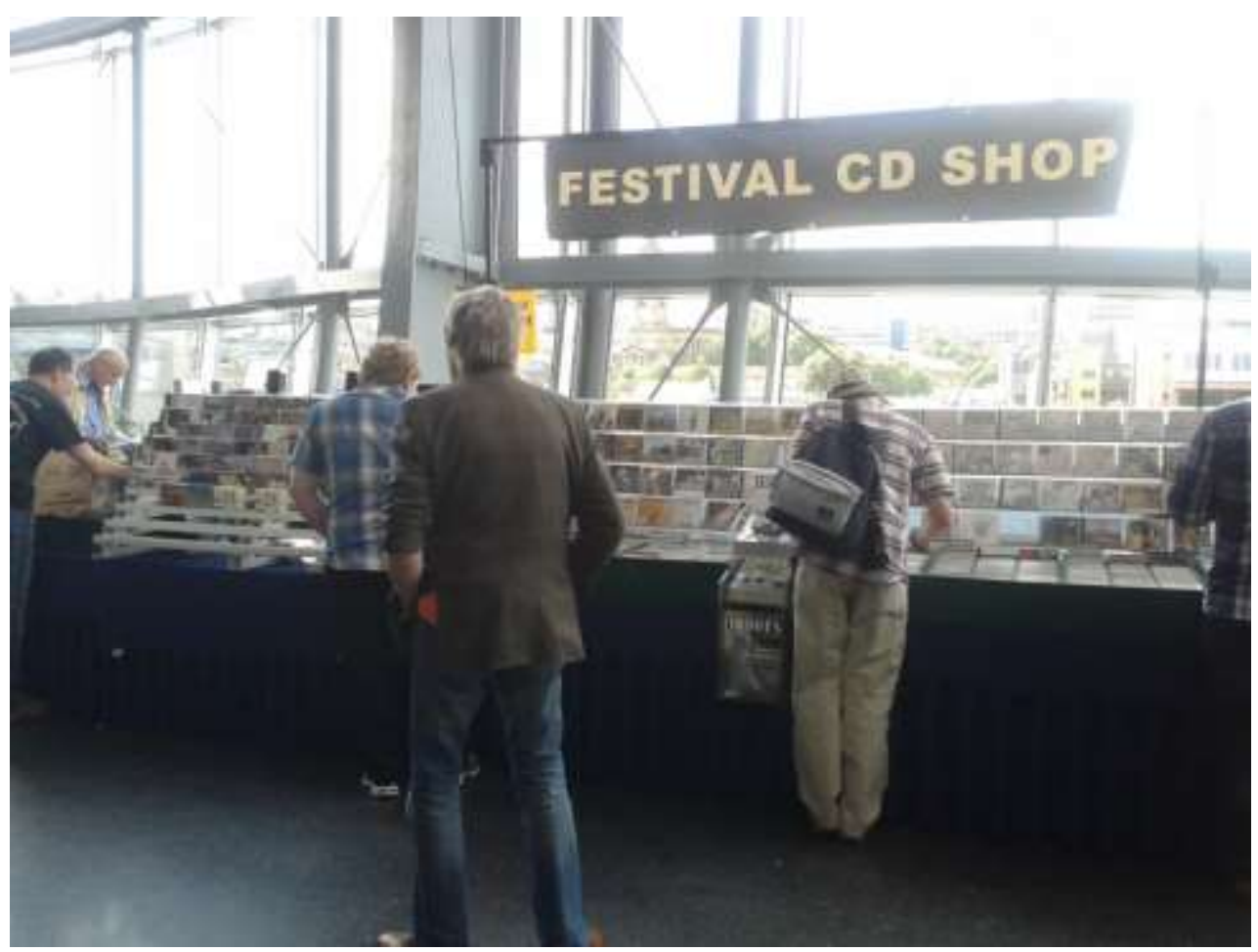

Figure 14. CD Shop on Concourse during Festival 


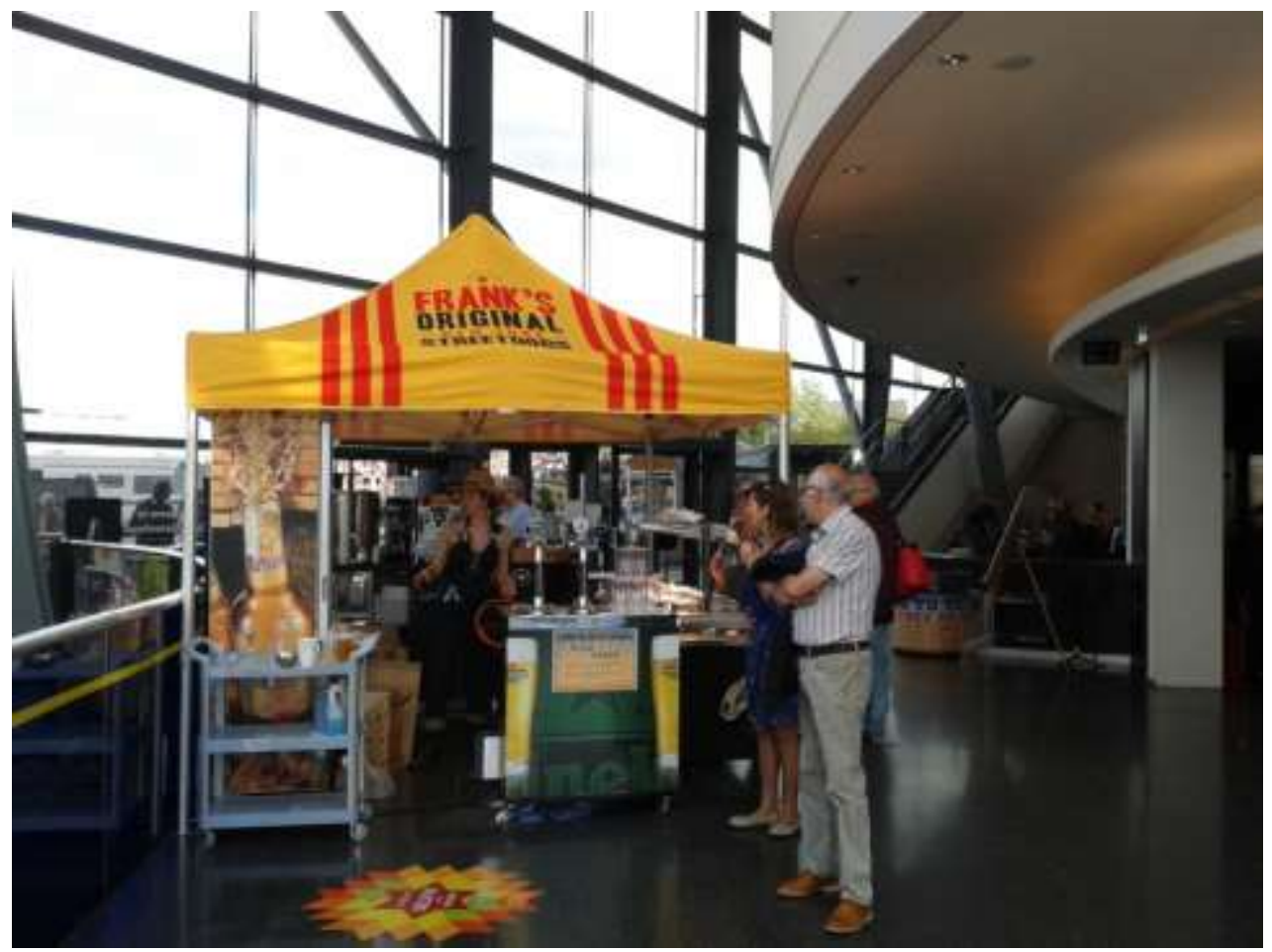

Figure 15. Kitchen Stalls

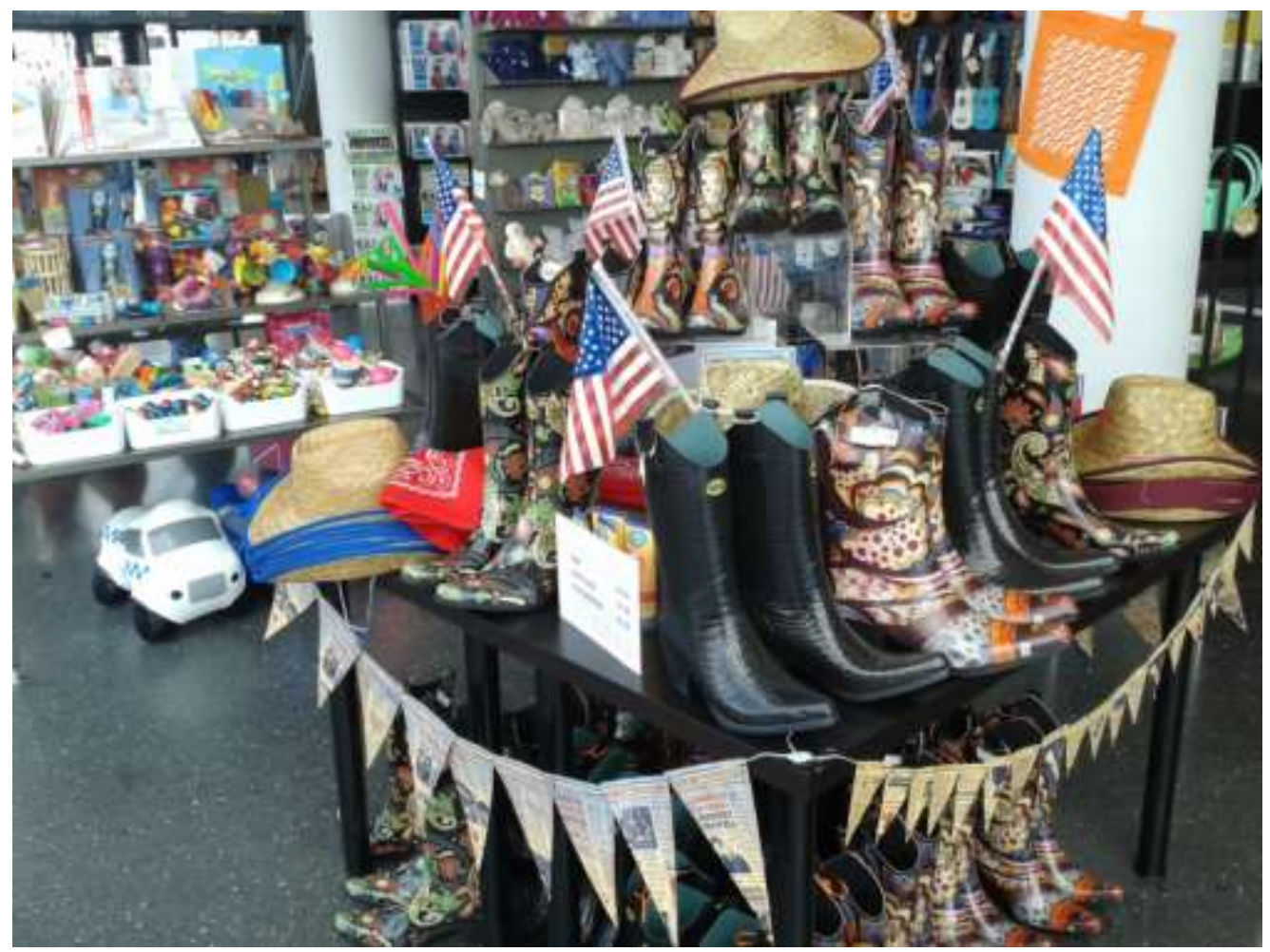

Figure 16. Cultural Products on Sale at Sage Gateshead Shop

SummerTyne Americana Festival is an annual weekend event held every summer which attracts visitors from across the world for a celebration of 
Americana music in and around the Sage Gateshead building. This weekend event showcases American roots music from both the UK and the US. ${ }^{40}$ The music programme is held in two halls, along with free stages, film programmes, poster exhibitions of arts and music, stalls of American cultural products, street kitchens and other attractions (Figures 14-18). An open-air stage is set up on the east side of the building, with a range of live music playing, including country, rock, folk, blues, vintage soul and so on. The sloping, arranged becomes a natural auditorium during such festivals. Live music is also programmed on a concourse stage inside the building, from soul choir to bluegrass, from gospel to ballad, and from country to rock. River cruises with live music are also included as one of the additional events.

During festivals, Sage Gateshead is at its most vibrant. Music events take place inside and around the building, attracting great numbers of visitors per day. A hundred visitors may be sitting, lying or standing on the landscaped lawn, watching the free stage showcase in the open air, while hundreds more are enjoying exhibitions, films and live music on the concourse inside the building, which makes the building crowded, sometimes even congested. It is interesting that, on walking from the east entrance to the west entrance through the concourse at such times, it comes to resemble a retail street made up of the Sage Gateshead shop, cafe and bar along one side of the "street" and food stalls, CD stalls, post exhibitions and stalls selling other cultural products along the other side (Figure 19).

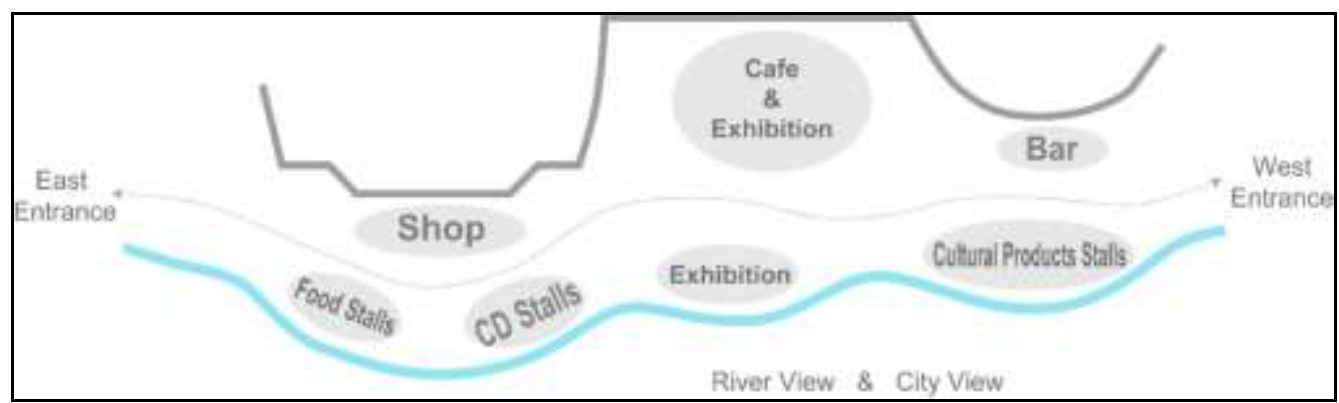

Figure 17. The Concourse Space Working as a Street during SummerTyne Americana Festival

The concourse is a polyvalent space, serving as free stage, exhibition space, pedestrian street, river-viewing stand, concert waiting room and assembly place, and so on. The essence of a polyvalent space is that it is a space containing multiple spatial typologies. The Sage Gateshead concourse contains at least five potential spatial prototypes. The prototype of a theatre, which has been discussed above, offers opportunities for the concourse to be a performing stage with the cafe and upper-level galleries becoming watching spaces. The prototype of an exhibition can require a spacious venue or a relatively closed and introverted space, depending on the theme of the exhibition, the scale of items in it and the atmosphere the items are intended to create. A pedestrian prototype demands wide

40. Sage Gateshead, SummerTyne Americana Festival (2017). 
and longitudinal space with attractions along two sides. A viewing stand should be located in a prominent position and should be matched with the lower-level landscape views. An assembling place requires a space for gathering which is able to accommodate a large number of people at certain times. It is possible for the concourse to play all of the above roles. However, it does not have a determined role prior to practical use.

A significant aspect of what Sage Gateshead offers is its "Join In and Make Music" programme. Join In and Make Music enables anyone of any age or ability to be involved in music. It covers early years, work with schools, vocal and instrumental learning, professional learning, community music, higher education and special training for people who have a disability. In addition to the work at the Sage Gateshead building itself, $70 \%$ of the activities of this programme take place in the communities it serves. Since opening in 2004, Sage Gateshead has provided music-making sessions to over a million people in more than 1,000 places across North East England. ${ }^{41}$

Join In and Make Music offer opportunities for adults in instrumental and vocal skills and plenty of opportunities for performing. Some even have chance to perform on stage with known performers. The "Silver Programme" provides a diverse range of musical activities for people over 50 particularly - joining a choir, playing an instrument, learning new skills and meeting new friends. According to a personal conversation with a participant in the Silver Programme, at present there are 52 bands involved in it. ${ }^{42}$ Participants can join more than one group. Participants are drawn from throughout the North East region, and the average age of participants is 60 . So far, 1,300 people have been registered to play in these groups.

There are also programmes for young people. A wide range of groups, courses and events are offered to young people. They have the chance to join bands, learn from the very best with Royal Northern Sinfonia and attend one of the summer schools. There are all kinds of family events taking place in the Greggs Children's Room at Sage Gateshead. Throughout most of the year, during termtime and school holidays, activities are provided for children and babies to enjoy with their families. Not only running programmes at the building, Sage Gateshead is also delivering "In Harmony" projects in communities. In Harmony is an immersive programme working with primary school children, to help them improve their life chances, social skills and educational attainment through learning an orchestral instrument. A wide range of other activities are also delivered in schools to support school curriculums and enrich music culture. Activities in settings across the region as well as at Sage Gateshead are available for all ages, abilities and stages. ${ }^{43}$

Professional music study and research are also a part of the programme. Degrees and relevant courses are offered, and welcome musicians who would love to build and develop professional careers in music. In studying music at Sage

41. Sage Gateshead, What we do.

42. A participant in the Silver Programme, personal conversation taken place at the Sage Gateshead building, July 6, 2015.

43. Sage Gateshead, Music for Young People (2017). 
Gateshead, one is not just learning instrument skills and practice, but one is doing so from inside those practices with a group of professional musicians from the UK's top organisations. The training programmes offer skills and training opportunities for people working in all aspects of music education and community music, across all genres, as well as devising and delivering specific training for professionals working in other sectors. Sage Gateshead's approach to training and workforce development helps to develop and sustain a diverse workforce for the creative and cultural sectors. ${ }^{44}$

In addition, people who have special needs are also considered in the programme. The "Accessible Learning Strand" supports access to music and musical learning opportunities for individuals who have special educational needs or disabilities. Experienced tutors and talented musicians will support participants in a relaxed, fun and friendly environment. Sage Gateshead also provides access for participation in employment-focused training supported by local partners. ${ }^{45}$ In such ways, Sage Gateshead becomes an extremely social-inclusive organisation which brings benefits for people of all ages and abilities.

\section{Conclusions}

Social engagement is essential for a city's well-being. Sage Gateshead, an iconic building, acts as a positive example that interprets its pragmatic role in generating and enhancing social engagement. The building's pragmatic role is embodied in its design concept, the management goals and the events taking place there. The building, therefore, is considered as a successful local project, since the idea of social engagement has been dynamically achieved and the pragmatic role has been specifically demonstrated.

The design concept, for Sage Gateshead, lies in the architects' ambitions of making the building an "Urban Living Room", represented in the form of textual and diagrammatic descriptions as well as the design of the physical space of the building. This concept comes from the architects' intention to understand and incorporate the function of the building, the circumstances of the site, social expectations and planning visions. As architects encounter these concerns, the concept arrives and the design is on its way to being shaped.

Once people get to use the space, these users come to have their own understandings of the building, and this is the way in which "pragmatic meaning" emerges. When events are carried out in the building day after day, "pragmatic meaning" increasingly grows in the building accordingly. "Pragmatic meaning" is neither unique nor permanent, but rather varies from time to time according to the different activities happening in the building and the people who are using the place. The physical space is created based on the design concept, which in turn provides room for actual experience, thus supporting the implementation of daily events and programmes. Since management goals and design concept have the same root of being concerned with social inclusion and diversity, events and

44. Sage Gateshead, Study Music at Sage Gateshead (2017).

45. Sage Gateshead, Accessible Music Learning (2017). 
programmes developed under management ideas correspond to the concept, therefore, the "pragmatic meaning" generated through actual experience further responds to the concept.

For Sage Gateshead, the concept exists prior to and independent from actual experience in the real space, and it is concerned with the liveliness of the space and with how the space is going to be used, thereby the concept is influenced by pragmatic concerns. As activities actually take place in the physical space, "pragmatic meaning" grows dynamically and enables the design concept to be realised in the space. Hence, in this way the concept and "pragmatic meaning" are associated and mutually impacted.

In brief, the design attitude this article tries to assert, is that a design concept is not merely about creating a symbolic image for a building, although symbolism is important for iconic buildings. The design concept ought to consider the way in which how space functions to promote better social engagement in the first instance, actual experience in real spaces needs to be a more central concern in the concept-making stage. Thus, a good architect might approach a commission with the intention of finding out the function of the building, the circumstances of the site, its culture, social demands, and will then work out a design that seeks to deal with all of these things, and at some point during this process a concept will arrive.

\section{Acknowledgments}

A particular gratitude should give to Professor Andrew Ballantyne for his suggestions in structuring the overall idea of the manuscript. The author is also grateful to the Sage Gateshead management teams for their permission for me to carry out my research in the building.

\section{Bibliography}

Abel, Chris and David Jenkins. Norman Foster: Works 5. Munich and London: Prestel, 2009.

Bailey, Christopher. "Cultural Values and Culture Led Regeneration - the Case of Newcastle-Gateshead." 14th International Conference of the ACEI. Vienna, 2006.

Foster and Partners. The Sage Gateshead UK 1997-2004. Available at: http://www.foster andpartners.com/projects/the-sage-gateshead/. [Accessed: March 23, 2016].

Hall, Peter. "Cultural Wisdom of Gateshead's Music Complex." Regeneration \& Renewal (May 2003): 14.

Hertzberger, Herman. Space and the Architect: Lessons in Architecture 2. Rotterdam: 010 Publishers, 2000.

Jones, Paul. The Sociology of Architecture. Liverpool: Liverpool University Press, 2011.

Miles, Steven. "Newcastle Gateshead Quayside: Cultural Investment and Identities of Resistance" (2004). Available at: https://bit.ly/2NwpZzS. [Accessed: September 2, 2015].

Miles, Steven and Malcolm Miles. Consuming Cities. New York: Palgrave Macmillan, 2004.

Miles, Stevens. “'Our Tyne': Iconic Regeneration and the Revitalisation of Identity in 
NewcastleGateshead." Urban Studies 42, no. 5/6 (2005): 913-26.

Newcastle City Council. Regeneration in Newcastle upon Tyne (2008). Available at: https://bit.ly/2CFKxC1. [Accessed: September 2, 2015].

Newcastle City Council. Gateshead Quays: Masterplan Report. Newcastle upon Tyne: Newcastle City Council, 2010. Available at: https://bit.ly/2oWspKi. [Accessed: September 2, 2015].

Newman, Mark A. "Urban Living Room - The Sage Gateshead Gives New Meaning to the Term 'Mixed Use'." Entertainment Design 39, no. 7 (2005): 20-3.

Sage Gateshead. Annual Review/September 2014-August 2015 (2015). Available at: https://bit.ly/2wXyFWA. [Accessed: February 28, 2016].

Sage Gateshead. Artistic Principles (2016). Available at: https://bit.ly/2NtQWUW. [Accessed: February 27, 2016].

Sage Gateshead. Equality and Diversity (2016). Available at: https://bit.ly/2NtRiee. [Accessed: February 27, 2016].

Sage Gateshead. SummerTyne Americana Festival (2017). Available at: https://bit.ly/1Yz KaII. [Accessed: February 25, 2017].

Sage Gateshead, Music for Young People (2017), available at: http://www.sagegateshead. com/join-in/music-for-young-people/ (Accessed: Feb 25, 2017).

Sage Gateshead. Study Music at Sage Gateshead (2017). Available at: https://bit.ly/2oWe UKK.. [Accessed: February 25, 2017].

Sage Gateshead. Accessible Music Learning (2017). Available at: https://bit.ly/2wYZ ARX. [Accessed: February 25, 2017].

Sainz, María A. "(Re)Building an Image for a City: Is A Landmark Enough? Bilbao and the Guggenheim Museum 10 Years Together." Journal of Applied Social Psychology 42, no. 1 (2012): 100-32.

Sargent, Anthony and Peter Buchanan. The Sage Gateshead: Foster + Partners. Munich and London: Prestel, 2010.

Sennett, Richard. The Fall of Public Man. London: Penguin, 2003.

Stephens, Suzanne. "The Sage Gateshead, England." Architectural Record 193, no. 8 (2005): 106.

Van der Graaf, Peter. "Out of Place? Emotional Ties to the Neighbourhood in Urban Renewal in the Netherlands and the United Kingdom." PhD thesis, University of Amsterdam, 2008. Available at: https://bit.ly/2O4Dy6M. [Accessed: September 2, 2015]. 